\title{
Software Para Prática De Regência Coral
}

\author{
Caio Cesar Moreira
}

\author{
DISSERTAÇÃO APRESENTADA \\ AO \\ INSTITUTO DE MATEMÁTICA E ESTATÍSTICA \\ DA \\ UNIVERSIDADE DE SÃO PAULO \\ PARA \\ OBTENÇÃO DO TÍTULO \\ $\mathrm{DE}$ \\ MESTRE EM CIÊNCIAS
}

Programa: Ciência da Computação

Orientador: Prof. Dr. Ronaldo Fumio Hashimoto

São Paulo, Novembro de 2013 


\section{Software Para Prática De Regência Coral}

Esta versão da dissertação contém as correções e alterações sugeridas pela Comissão Julgadora durante a defesa da versão original do trabalho, realizada em 23/11/2013. 


\section{Software Para Prática De Regência Coral}

Esta versão da dissertação contém as correções e alterações sugeridas pela Comissão Julgadora durante a defesa da versão original do trabalho, realizada em 23/11/2013.

\section{Comissão Julgadora:}

\section{Titulares:}

- Prof. Dr. Ronaldo Fumio Hashimoto (Presidente) IME - USP

- Prof. Dr. Carlos Hitoshi Morimoto IME - USP

- Prof. Dr. Marco Antonio da Silva Ramos ECA - USP

Suplentes:

- Prof. Dr Roberto Hirata Junior

IME - USP

- Profa. Dra. Susana Cecília Almeida Igayara de Souza ECA - USP 


\section{Agradecimentos}

Agradeço a Aline Yukari Tozaki por ter me dado todo suporte necessário para conseguir seguir cada dia, por me inspirar, conscientizar-me de mim mesmo, e ser meu porto seguro.

Ao professor Marco Antônio da Silva Ramos por compartilhar de seus sonhos comigo. Ao professor Ronaldo Fumio Hashimoto por ter acreditado em mim durante todo o curso.

À ciência, que nos dá o poder da criação e de realizar sonhos. 


\section{Resumo}

MOREIRA, C. C. Software Para Prática De Regência Coral. 2013. 60 f. Dissertação (Mestrado) - Instituto de Matemática e Estatística, Universidade de São Paulo, São Paulo, 2013.

Neste documento um software é proposto para apoiar o ensino da regência coral com base em um modelo de aula padrão observado na disciplina: Análise Musical para Performance: Interfaces entre Criação e Interpretação a Partir do Universo Coral do Departamento de Música da Escola de Comunicações e Artes da Universidade de São Paulo. Neste software é possível: (i) monitorar, (ii) mensurar e (iii) avaliar os padrões de regência (gestos) de regência realizados e as posições corporais de um estudante de regência coral. O principal objetivo é permitir, através da interação com o software, que o estudante possa aprimorar sua consciência corporal através do monitoramento de seu posicionamento espacial enquanto realiza os padrões de regência e se vê projetado tridimensionalmente no sistema. Para que este monitoramento seja suportado, três módulos foram criados, de modo que as devidas configurações possam ser realizadas, assim como a visualização seja feita, a saber: (a) módulo de configuração de padrões de regência, onde padrões de regência são criados ou modificados; (b) módulo de criação de práticas, que podem ser: (b.1) sintéticas, e neste caso utilizam os padrões de regência pré-definidos em (a), dispondo-os em sequências ao longo do tempo as quais são associadas às mãos do regente, ou (b.2) gravadas, onde através do registro de movimentos corporais por um período de tempo em frente ao sensor, as juntas corporais são capturadas ao longo do tempo, de modo que se possa comparar estes movimentos com os realizados em tempo real; e (c), o módulo de visualização, onde o usuário poderá (c.1) assistir a reprise de práticas já realizadas, ou configuradas anteriormente; (c.2) comparar e visualizar práticas diversas entre si; ou ainda, (c.3) praticá-las de fato, onde receberá uma nota ao final do exercício. A idéia é que estudantes possam realizar práticas repetidas vezes, onde irão melhorando suas notas, e aprimorando seus gestos através da conscientização corporal. Outro ponto importante é que estudantes e regentes podem interagir entre si através da troca das configurações, já que estas são salvas em arquivos, possibilitando a criação de um repositório de regência coral, o que permite que as informações extrapolem os limites de sala de aula. Para implementar tal solução, algoritmos de visão computacional foram aplicados no contexto da regência coral, em conjunto com o sensor Kinect para auxiliar na captura das informações corporais. Por fim, busca-se iniciar um trabalho com o sentido de aprimorar a formação de regentes e possibilitar que o ensino desta arte seja fundamentado em dados quantitativos que poderão auxiliar o regente a tirar conclusões sobre os métodos e escolas de regência atualmente existentes.

Palavras-chave: regência coral, padrões de regência, Kinect, visão computacional, consciência corporal, avaliação, interatividade. 


\begin{abstract}
MOREIRA, C. C. Software For Choral Conducting. 2013. 60 f. Dissertação (Mestrado) Instituto de Matemática e Estatística, Universidade de São Paulo, São Paulo, 2013.

In this document a software to support the teaching of choral conducting is proposed based on the conducting classes observed while coursing the discipline: Musical Analysis for Performance on the Choral Universe in the Music Department of the School of Arts and Communications of University of Sao Paulo. Through this software is possible to: (i) monitor, (ii) measure and (iii) evaluate the choral conducting patterns (gestures) performed and the body positions of the student. The main objective is to allow, by interacting with the software, that the student improves his body self-perception by having his body position monitored while he performs the conducting patterns and sees himself tridimensionally projected in the system. To have this monitoring in place, three modules were created such that the needed configurations could be done as well as the visualization could have been done, they are: (a) conducting patterns configuration module, where the conducting patterns are created or modified; (b) practice creation module, the practices can be (b.1) synthetical, in this case they use the conducting patterns defined in (a), placing them in sequences accross the time which are associated to the hands of the conductor, or (b.2) recorded, in which case the body movements are recorded for a period of time in front of the sensor, the positions are stored along time and allow to compare these movements recorded with the user information in realtime; and (c), the visualization module, where the user can (c.1) watch a replay of the practices already performed, or configured previously; (c.2) compare and see diversified practices, or yet, (c.3) effectivelly practice them, in which case an evaluation mark will be given at the end. The idea is that students can do and repeat practices over, improving their marks and gestures through self-perception. Another important point is that students and conductors can interact by exchanging configurations, since all of them are saved in files, which allows creating a choral conducting repository which would extrapolate the classroom boundaries. To implement such solution computer vision algorithms were applied in the context of choral conducting, together with the Kinect sensor to help capturing the body information. At last, this work tries does the kick off for teaching conductors through the usage of technology, allowing that this art is teached based on quantitative data which can help the conductor drawing conclusions over the current conducting schools and methods.
\end{abstract}

Keywords: choral conductor, conducting patterns, Kinect, computer vision, body selfperception, evaluation, interactivity. 


\section{Sumário}

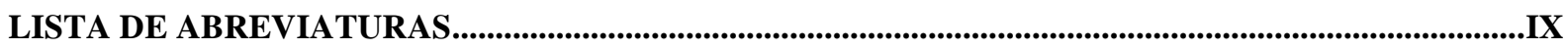

LISTA DE FIGURAS ……............................................................................................................................................... X

LISTA DE TABELAS............................................................................................................................. XII

CAPÍTULO 1: INTRODUÇÃO ...................................................................................................................... 1

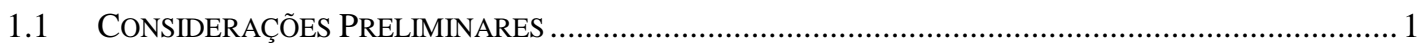

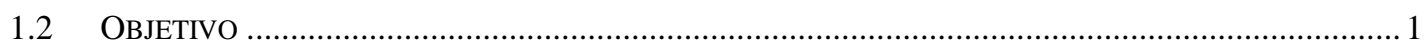

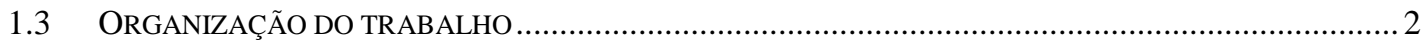

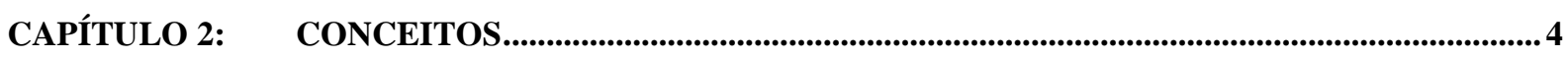

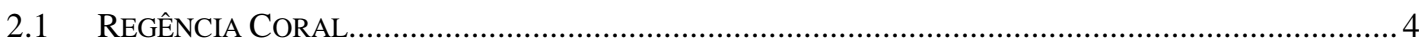

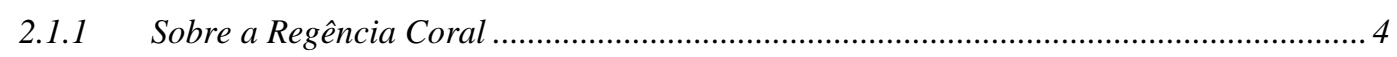

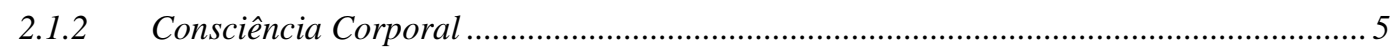

2.1.3 Ensino da Regência Coral.......................................................................................

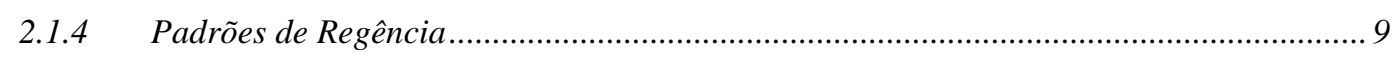

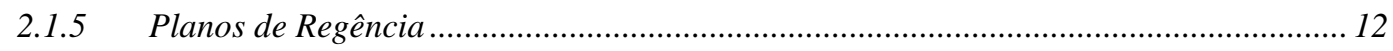

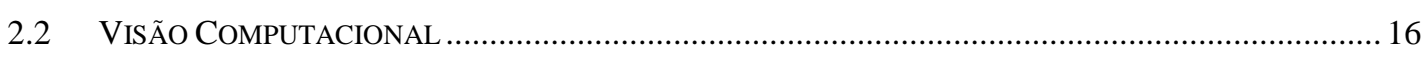

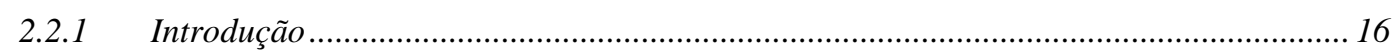

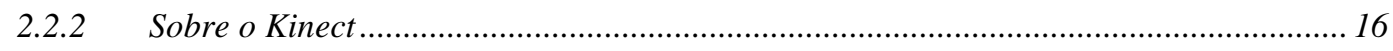

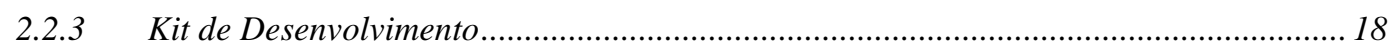

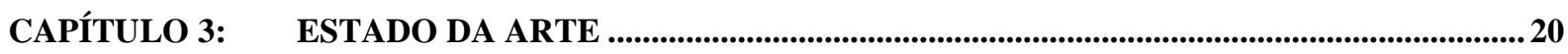

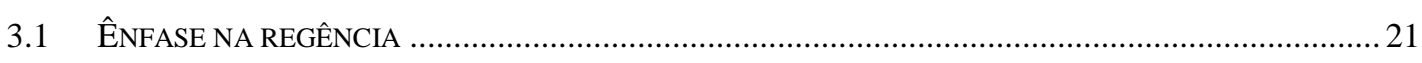

CAPÍTULO 4: SOFTWARE PARA ENSINO DE REGÊNCIA CORAL ................................................2 24

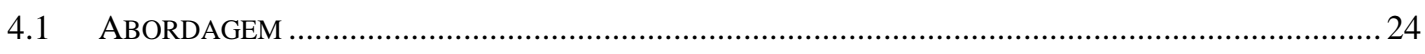

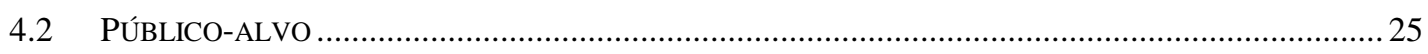

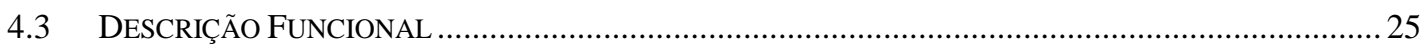

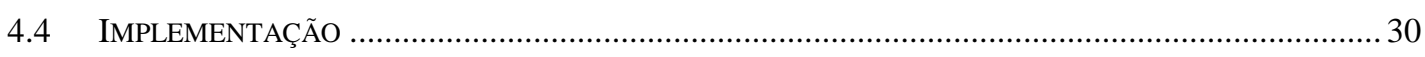

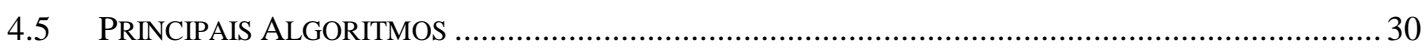

4.5.1 Interpolação de Pontos de Controle para Gerar Padrão de Regência .............................. 30

4.5.2 Escala e Rotação Horizontal dos Padrões de Regência ................................................ 31

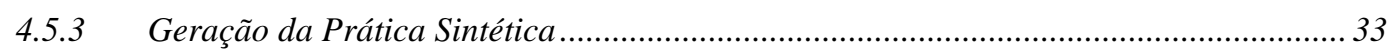


4.5.5 Algoritmo de Detecção Automática dos Tempos nos Padrões de Regência..................... 40

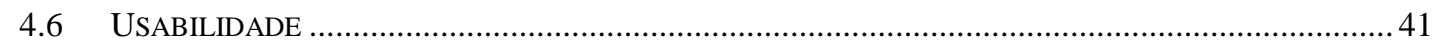

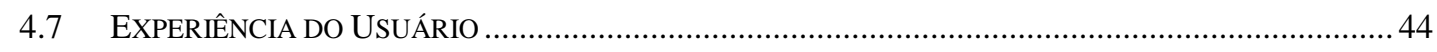

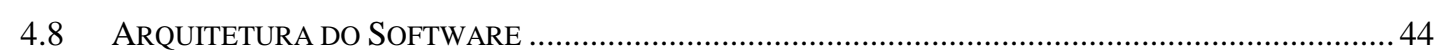

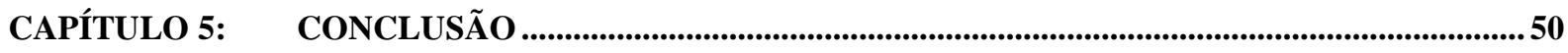

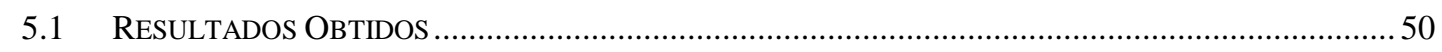

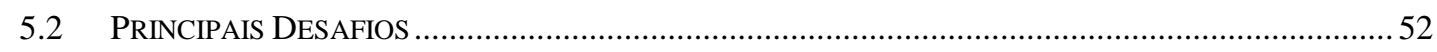

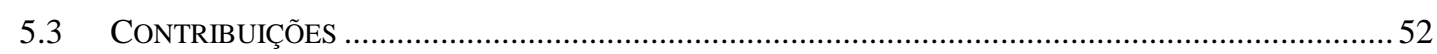

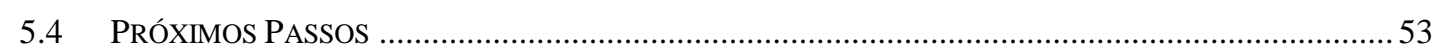

CAPÍtULO 6: REFERÊNCIAS BIBLIOGRÁFICAS ...............................................................................5 54 


\section{Lista de Abreviaturas}

LER Lesão por Esforço Repetitivo

HMM Hidden Markov Models

ICMC International Computer Music Conference

SDK Source Development Kit - Kit de Desenvolvimento de Código

SEI Software Engineering Institute

USB Universal Serial Bus

XML Extensible Markup Language (XML) - Linguagem de Marcação Extensível

XNA Framework de computação gráfica da Microsoft ${ }^{\circledR}$ 


\section{Lista de Figuras}

FIGURA 1 - RoBERT GARRETSON: PADRÃO DE REGÊNCIA DE 4 TEMPOS. ................................... 10

FIGURA 2 - RoBERT GARRETSON: PADRÃO DE REGÊNCIA DE 4 TEMPOS. ................................... 10

FIgURA 3 - KURT THOMAS: PADRÃo DE REGÊNCIA DE 4 TEMPOS............................................. 10

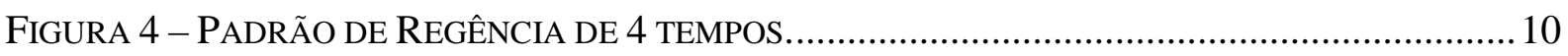

FIGURA 5 - TEMPOS QUATERNÁRIOS EM DIVERSAS ARTICULAÇÕES ….................................... 11

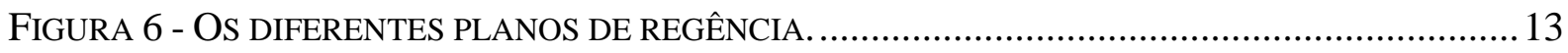

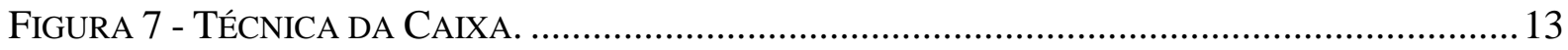

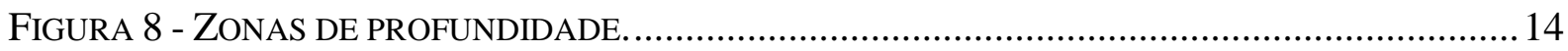

FIGURA 9 - AS DIFERENTES ALTURAS NO CUBO DE RAMOS (2011)..................................... 14

FIGURA 10 - AS DIFERENTES LARGURAS NO CUBO DE RAMOS (2011)................................... 14

FIGURA 11 - AS DIFERENTES PROFUNDIDADES NO CUBO DE RAMOS (2011). ......................... 14

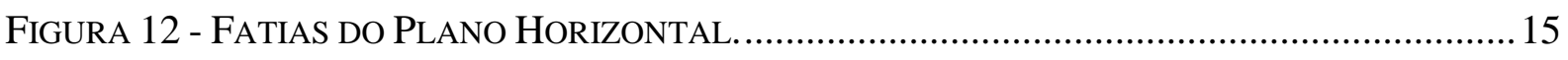

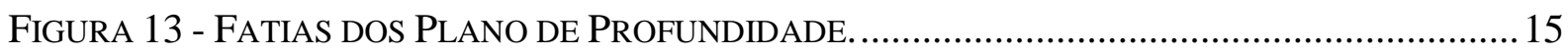

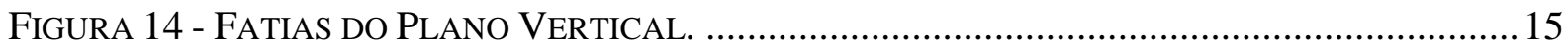

FIGURA 15 - PRECISÃO MÉDIA COMPARANDO PREDIÇÃO DE JUNTAS ATRAVÉS DE JUNTAS INFERIDAS E JUNTAS EXTRAÍDA A PARTIR DOS MAPEAMENTOS VERDADEIROS. .................... 18

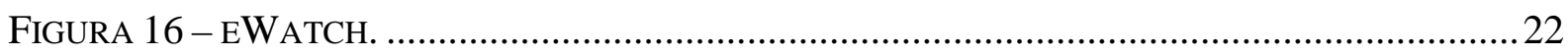

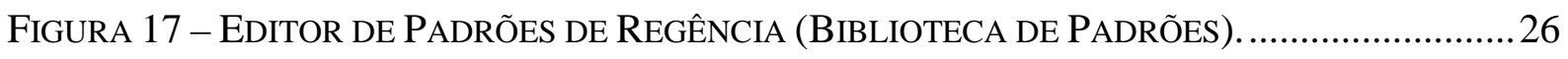

FIGURA 18 - PRÉ-SELEÇÃO DE PADRÕES DE REGÊNCIA DEFINIDOS EM (1) .................................27

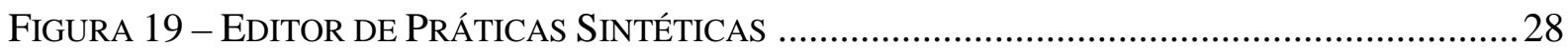

FIGURA 20 - GERENCIADOR DE PRÁTICAS GRAVADAS ..........................................................29

FIGURA 21 - ESCALA ENTRE PADRÃO ORIGINAL E PADRÃO REDIMENSIONADO PELO USUÁRIO....32

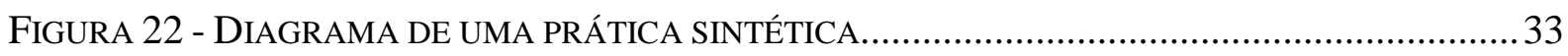

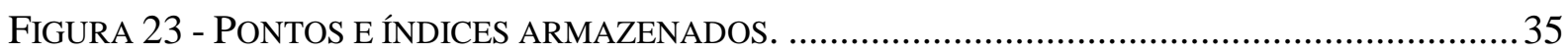

FIGURA 24 - PADRÃO DE REGÊNCIA E OS VALORES DE M E N..................................................... 35

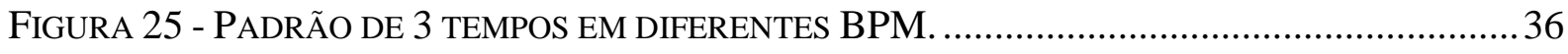

FIGURA 26 - EXEMPLO DE PADRÃO DE REGÊNCIA DE 4 TEMPOS P1 ......................................... 37

FIGURA 27 - EXEMPLO DE PADRÃO DE REGÊNCIA DE 2 TEMPOS P2 …........................................ 37

FIGURA 28 - COMPARAÇÃO DE FRAMES DE DOIS CONJUNTOS F E F' ..........................................39 
FIGURA 29 - VISÃO GERAL DA INTERAÇÃO HOMEM-COMPUTADOR .......................................... 43

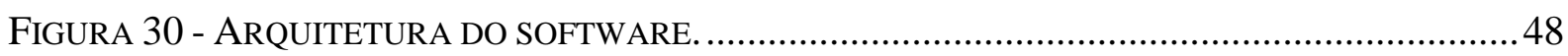

FIGURA 31 - PRÁTICA SINTÉTICA UTILIZADA PARA TREINAMENTO. .........................................50

FIGURA 32 - ANÁLISE DO RESULTADO DOS TREINAMENTOS. ..................................................51 


\section{Lista de Tabelas}

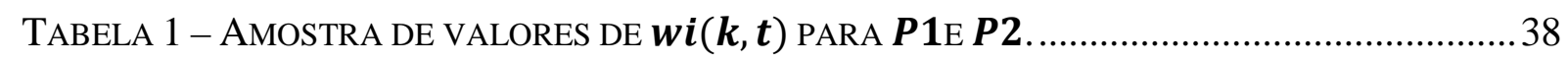

TABELA 2 - XML REFERENTE AO PADRÃO EXIBIDO NA FIGURA 17 ........................................... 46

TABELA 3 - XML DE REPRESENTAÇÃO DE PRÁTICA GRAVADA ….............................................. 48

TABELA 4 - RESULTADO DE 10 TREINAMENTOS CONSECUTIVOS PARA 5 USUÁRIOS. ...................51 


\section{Capítulo 1: Introdução}

\subsection{Considerações Preliminares}

O presente trabalho propõe um software interativo para o ensino da regência coral fundamentado pelos conceitos apresentados nas próximas seções, mas principalmente com base no método de aula apresentado na Seção 2.1.3 (Ensino da Regência Coral).

É importante dizer que através deste software, busca-se fornecer uma ferramenta de apoio ao ensino da regência coral, de modo a contribuir com informações além das que podem ser obtidas pelos métodos tradicionais atuais utilizados em salas de aula. Entretanto, não pretende, de forma alguma, restringir a expressão do regente, como artista que é.

Quanto ao software apresentado, todo e qualquer código utilizado foi criado pelo autor do presente trabalho o qual se valeu dos conhecimentos advindos de disciplinas cursadas na Escola de Comunicações e Artes desta Universidade, em conjunto com as disciplinas de Visão Computacional ministradas no Instituto de Matemática e Estatística, além dos materiais citados no Capítulo de Referências Bibliográficas deste documento.

\subsection{Objetivo}

Segundo RAMOS (2003), há uma enorme distância entre o processo de iniciação à regência e o momento em que se dá o domínio técnico e artístico que permite exercer a regência de fato. Portanto, o presente trabalho propõe um software de auxílio (apoio) aos processos de ensino e aprendizagem da regência coral, permitindo:

- Criação de padrões de regência;

- Criação de práticas de regência;

- Visualização, execução e avaliação das práticas criadas ou executadas anteriormente. 
Estas funcionalidades são baseadas nos modelos de aula observados durante as disciplinas de regência coral e buscam trazer principalmente a consciência corporal para o estudante de regência, já que este ainda não está familiarizado com os principais parâmetros da regência ${ }^{1}$.

Do ponto de vista do professor de regência coral, o software permite que vários alunos realizem uma mesma prática pré-definida e que os resultados possam ser comparados entre alunos, ou com diferentes momentos de prática do mesmo aluno, de modo que o professor consiga verificar a evolução deste ao longo de um período de tempo. Outro benefício é a descentralização da prática da regência, fazendo com que esta ultrapasse os limites da sala de aula, já que um aluno poderia praticar a regência em sua casa, em seu computador, da mesma forma com que faria em sala de aula, obtendo um feedback logo após o término da execução da prática através de uma nota. Desta forma, acredita-se que a aplicação desenvolvida está alinhada com os parâmetros escolhidos (posição da coluna, padrões e planos de regência) e que são comumente os primeiros a serem trabalhados em sala de aula.

\subsection{Organização do trabalho}

No Capítulo 1 são apresentados os principais objetivos deste trabalho, onde são expostos brevemente os principais tópicos a serem tratados ao longo do texto e as principais áreas que se beneficiam com a criação do software.

O Capítulo 2 foca em conceitos necessários para a compreensão do problema e do universo o qual este está inserido, assim como explica os conceitos necessários para a compreensão da solução apresentada. Ele está dividido em duas subseções: a regência e a visão computacional, principais áreas do conhecimento utilizadas nesta dissertação.

No Capítulo 3 são apresentados os mais recentes softwares desenvolvidos utilizando as tecnologias abordadas, buscando sempre focar na regência coral. No Capítulo 4, o software é descrito arquiteturalmente, funcionalmente e tecnicamente, cobrindo as técnicas e algoritmos utilizados.

\footnotetext{
coluna).

${ }^{1}$ Parâmetros de regência são medidas obtidas através de informações corporais (e.g. rotação da
} 
No Capítulo 5 são listados os resultados obtidos com o uso da aplicação, os principais desafios encontrados, as áreas que podem ser beneficiadas com o software e os próximos passos para aprimorá-lo.

Por fim, no Capítulo 6, referências são listadas para serem utilizadas como fonte de consulta. 


\section{Capítulo 2: Conceitos}

Por este trabalho ser multidisciplinar, faz-se necessário introduzir conceitos de ambas áreas: regência coral e visão computacional, já que leitores destas podem não conhecer os conceitos básicos da outra, e vice-versa.

\subsection{Regência Coral}

\subsubsection{Sobre a Regência Coral}

É importante iniciar este trabalho citando Robert Garretson - um dos professores de regência coral mais influentes do século $\mathrm{XX}$ e o qual exerceu importante papel na regência através da Universidade de Colorado. Segundo ele:

“A função básica do regente é interpretar a música para os coralistas. Através de meios variados ele favorece e instiga vida e vitalidade na música - resultado o qual pode ser uma experiência estética arrepiante e genuína para ambos os participantes $e$ audiência escutante. O regente precisa ser mais do que um mero marcador de tempo. O seu conhecimento musical e seus desejos interpretativos deverão ser representados através de sua técnica de regência. É claro, a importância de demonstrações e expressões verbais não deverá ser minimizadas, mas durantre os ensaios, explicações verbais extensas deverão ser mantidas ao mínimo. É através de sua técnica que o regente experiente poderá mais rapidamente ajudar o grupo alcançar interpretação desejada” (GARRETSON , 1998).

Isso dito, pode-se verificar que toda dinâmica e coordenação das vozes e da música é ditada e gerenciada pelo regente, que interpreta a partitura, convertendo-a em gestos, os quais são transmitidos ao coro, produzindo o resultado final. Entretanto, é importante notar que uma mesma partitura pode ser interpretada diferentemente por regentes distintos e até mesmo um único regente; caso desejar, pode este realizar distintas interpretações e comandá-las às vozes que compõe o coral, à medida que for necessário.

Esta sinergia e entrosamento exigem treinamento constante de ambos os lados: (i) do regente, que deverá possuir clareza de movimentos e uma boa expressividade; e 
(ii) de cada uma das vozes do coro, as quais deverão estar aptas a reconhecer tais comandos e expressá-los de maneira fiel e precisa.

Segundo RAMOS (2003), uma das principais diferenças entre o regente de uma orquestra e o regente coral, é que o último não usa batuta, que é um amplificador do gesto. Sem amplificação, o gesto que é grande frente a uma orquestra, por exemplo, pode ficar acanhado frente a um coro. Há, portanto, a necessidade de que a regência coral se mostre adequada a este dado de realidade.

E no que diz respeito a regência coral, conforme CHESNOKOV (2010), os principais componentes de sucesso de um coral, são: (a) conjunto - todos os indivíduos dentro de sua respectiva seção do coral (naipe), dentro do coro, deverão estar balanceados, unidos e unificados; $(b)$ entonação - cada indivíduo deverá estar atento à sua volta de maneira que sua própria entonação seja regulada para preservar a união e a harmonia do conjunto; e $(c)$ nuance: cada indivíduo deverá manter contato visual com o regente para que a liderança do regente possa atuar sobre os coralistas, dando-lhes maior percepção da sonoridade gerada pelo coro e conscientizando-os das pequenas nuances pelas quais são responsáveis. Segundo DECKER \& HERFORD (1988), o tipo e a qualidade do tom produzido por um coral é influenciado primariamente pelo que o regente faz, o que mais uma vez revela sua importância.

Desta forma, o regente precisa estar atento a todos os fatores mencionados acima, e para isso, é necessário que este seja preparado apropriadamente, o que implica forte conhecimento teórico e uma parte igualmente importante de treinamento técnico e físico, o que inclui memorizar sequências de movimentos e gestos específicos, que se constituirão em um repertório pessoal, ainda que pré-convencionado (GEHRKENS, 2007).

O presente trabalho busca trazer uma contribuição que possa ajudar à ampliação da consciência corporal de um regente iniciante, ao mesmo tempo em que provê meios e insumos para o professor de regência coral avaliar a evolução de seus alunos, além de permitir que seu trabalho tenha um alcance além dos limites da sala de aula.

\subsubsection{Consciência Corporal}


Em termos do estudo da regência coral utilizaremos o termo consciência corporal como a leitura que o regente faz do posicionamento no espaço e da expressividade necessária das diferentes partes de seu corpo em movimento. Partindo de exemplos da vida cotidiana, vemos que é muito comum pessoas adotarem uma postura prejudicial ao seu próprio físico, seja ao dirigir, ao trabalhar, ao comer, ao jogar seus games ao computador, ao caminhar, ao tocar um instrumento musical e, portanto, não seria diferente ao reger um coral. Entretanto, além dos males físicos que uma má postura acarreta, no caso da arte, isso traz consequências ainda mais extensas. Por exemplo, uma bailarina não conseguirá expressar o máximo de sua arte através de uma postura incorreta no palco durante uma apresentação, o mesmo também ocorre para o regente, que usa sua postura como base para os gestos de regência utilizados para se comunicar com o coral. A postura é parte inerente da técnica.

No mesmo sentido do que foi mencionado, RAMOS (2003), diz que a primeira necessidade do regente coral é encontrar para si uma postura física apropriada, evitando futuros problemas com as temíveis LER (Lesões por Esforço Repetitivo); (a) seja em busca de um exemplo postural para o coro - fator determinante na produção vocal; (b) seja em busca de melhor visibilidade para seu gestual - fator indispensável na comunicação entre coro e regente; (c) seja na garantia de organicidade ao conjunto de sua movimentação - fator de integração das muitas vertentes físicas, teóricas e expressivas presentes na performance do regente enquanto tal.

EHMANN (1968) afirma que os gestos em regência funcionam como a exteriorização do pensamento musical criado na mente do regente após a análise do material que estuda. Estes gestos, ao agirem através dos músicos (coralistas), geram um determinado resultado sonoro que, segundo BRANCO (s.d), deve ser observado pelo regente, de modo a ajudá-lo na construção de movimentos adequados, antecipando assim o som desejável.

Logo, pode-se dizer que a regência é uma disciplina de interpretação que, por sua vez, pertence à área da comunicação. Assim, para que a última ocorra, é necessário que o receptor compreenda o que foi transmitido pelo emissor, e isso só ocorrerá se houver clareza na mensagem transmitida, denotando a importância da postura do regente. 
De acordo com RAMOS (2003), o cerne da regência está ligado, por um lado, a um conjunto de atitudes técnicas que buscam clareza e comunicabilidade no contato com os músicos e coralistas e, por outro, a uma capacidade de estabelecer contato emotivo direto através da utilização do corpo e da expressão facial. O mesmo autor ainda diz que é necessário aprender o gestual específico, em busca das habilidades físicas que permitam a instalação de um processo de comunicação não verbal ativo e eficiente.

O regente iniciante aprende a postura correta e os gestos através de:

- modelo fornecido pelo professor;

- pela observação de regentes em ação;

- pela literatura.

E o domínio desta técnica depende dos seguintes fatores:

- compreensão da postura e dos gestos (padrões de regência);

- memorização dos mesmos;

- repetição (treinamento) constante para que o estudante consiga incorporar o movimento, de modo totalmente interiorizado - descrito por RAMOS (2003) como "memória geográfica".

No entanto, este processo de aprendizagem deve ser feito com a supervisão adequada pois, do contrário, vícios de regência podem surgir. Segundo GARRETSON (1998), é essencial que o regente possa eliminar seus traços e hábitos incorretos durante o aprendizado da regência, de modo que eles não sejam reforçados e tornem-se habituais.

O uso do espelho e filmagens para aprimorar a consciência corporal é utilizado há muito tempo por regentes, e sua eficácia existe, entretanto, é interessante para estudantes e professor comparar movimentos atuais com movimentos anteriores, ou ainda, movimentos realizados entre diferentes regentes, que a prática tradicional através dos métodos citados não permite.

\subsubsection{Ensino da Regência Coral}

O modelo de aula descrito adiante foi observado na disciplina de regência coral (“Análise Musical para Performance: Interfaces entre Criação e Interpretação a Partir 
do Universo Coral") da Escola de Comunicação e Artes da Universidade de São Paulo ministrada pelo professor Dr. Marco Antonio da Silva Ramos, seguindo sua metodologia. Este modelo (formato de aula) poderá variar conforme a escola de regência. Entretanto, os elementos técnicos que compõe as partes da aula são técnicas inerentes ao ensino da regência coral e deveriam ser trabalhados em algum momento por qualquer escola de regência.

\section{Parte 1: Ensino de novo elemento de regência}

- Os alunos se posicionam em volta do professor, formando uma grande roda;

- O professor ensina e demonstra os novos conteúdos gestuais aos alunos, para que todos possam ver. Geralmente os esquemas gráficos dos novos gestos são desenhados na lousa pelo professor;

- Os alunos então executam individualmente o novo gesto. Outras maneiras de execução são: em pares; a prática em frente ao espelho; entre outras - a idéia é que os alunos passem a perceber os gestos, conscientizando-se dos mesmos, e assim, consigam aprimorar suas noções corporais;

- O professor passa uma sequência de gestos para os estudantes executarem.

\section{Parte 2: Distribuição de nova partitura}

- O professor distribui uma nova partitura (música) aos alunos e a repassa com os alunos para que possam compreendê-la;

- Um aquecimento vocal ${ }^{2}$ é realizado com todos ao mesmo tempo;

- O professor organiza o coral em naipes ${ }^{3}$.

\section{Parte 3: Prática da regência}

\footnotetext{
${ }^{2} \mathrm{O}$ aquecimento vocal também é conhecido como "vocalise" ou vocalização. No caso das aulas do professor de regência coral citado, este momento tem também a função de ensinar a ensinar a cantar em coro. Cada exercício realizado é analisado em seus objetivos técnicos e finalidades pedagógicas.

${ }^{3}$ Naipe é um agrupamento de coralistas conforme seus tipos de voz (e.g. tenor, baixo, soprano, contralto, etc).
} 
- Os estudantes de regência participam como coralistas, enquanto são regidos pelo professor ou por outro aluno - isso lhe permite observar os gestos do regente e notar como o coro se comporta à medida que estes são realizados;

- Em seguida, um estudante troca de lugar com quem estava regendo, e passa a reger o coro - o professor observa o regente, que ao final da execução da música recebe conselhos, críticas e elogios do professor;

- Por fim, o regente retorna ao coro dando lugar a um novo estudante que regerá em seu lugar e isso ocorre inúmeras vezes acompanhado da supervisão do professor.

O ciclo descrito na Parte 3 se repete, e idealmente, deveria ocorrer para cada um dos estudantes. Entretanto, como as aulas possuem um tempo máximo, na maioria das vezes, somente parte dos estudantes tem chance de atuar como regentes.

Como pôde ser observado acima, a relação professor-estudante na regência é dada pela difusão do conhecimento, observação e análise. Estes três elementos podem ser facilitados através do uso da tecnologia, a qual pode ser utilizada para armazenar o conhecimento e trabalhar sobre o mesmo. Com a tecnologia é possível extrair dados precisos da cena (e.g. coordenadas tridimensionais de cada junta corporal do regente), permitindo análises automáticas e gravações que poderiam ser visualizadas em momentos posteriores.

\subsubsection{Padrões de Regência}

Os livros de regência costumam discorrer sobre os gestos de regência usando principalmente três informações: (a) esquemas gráficos, isto é, ilustrações gráficas dos padrões de regência; (b) explicações descritivas; e (c) exemplos musicais que ajudam a entender o caráter dos mesmos. Abaixo pode-se verificar padrões de regência ${ }^{4}$ para o compasso musical ${ }^{5}$ de 4 tempos:

\footnotetext{
${ }^{4} \mathrm{O}$ padrão de regência é um dos gestos realizados pelo regente para marcar o tempo da música e pode ser considerado um tipo de gesto realizado.

${ }^{5} \mathrm{O}$ compasso musical define quantos pulsos ocorrem dentro de intervalo de tempo.
} 


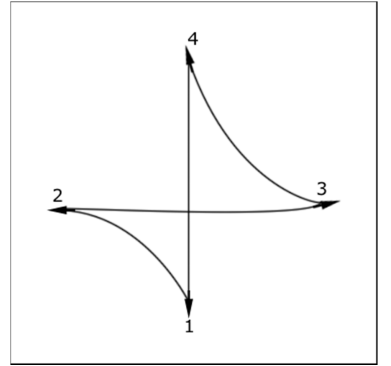

Figura 1 - Robert Garretson:

Padrão de Regência de 4 tempos.

Fonte: Garretson, 1998.

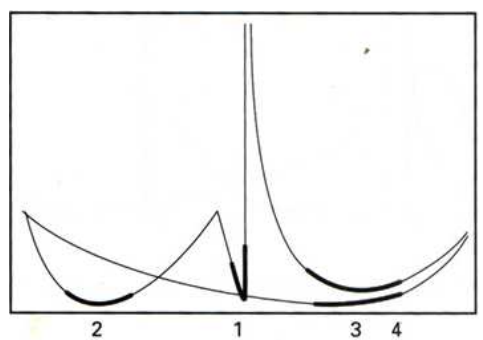

Figura 4 - Padrão de Regência de 4 tempos.

Fonte: DEMAREE \& MOSES,

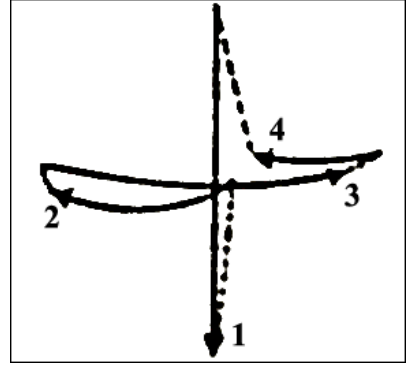

Figura 2 - Robert Garretson:

Padrão de Regência de 4 tempos.

Fonte: Garretson, 1998.

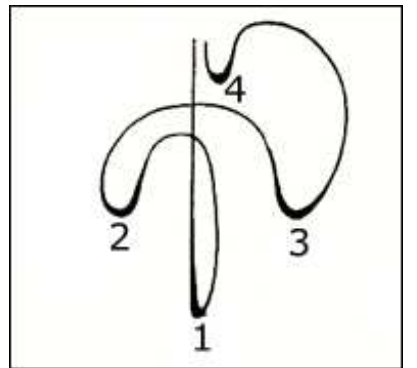

Figura 3 - Kurt Thomas:

Padrão de Regência de 4 tempos.

Fonte: Thomas, 1971.

1995.

Todos os gráficos acima são capazes de localizar o músico nos tempos do compasso (as partes de um todo). Entretanto, as formas dos esquemas exemplificados são diferentes em função de terem surgido em escolas de regência ${ }^{6}$ diferentes e as respectivas coerências de suas construções técnicas.

Nos padrões de regência, cada número representa a marcação de um tempo ("batida") e as linhas representam o percurso a ser realizado pela mão do regente. O movimento é iniciado, pelo menos, um tempo antes daquele onde a música de fato começa. Depois, entra no esquema padrão ${ }^{7}$ e se repete sequencialmente.

A velocidade com que o movimento é realizado, dependerá de quantas batidas por minuto ("BPM") são utilizadas pela música. Uma BPM de 60 significa que em 1 minuto são realizadas 60 batidas, isto é, marcações de tempo. No exemplo de um

${ }^{6} \mathrm{O}$ presente trabalho não discutirá as diferentes escolas de regência por não ser seu objeto, mas adiantamos que a ferramenta tecnológica desenvolvida pode adaptar-se a elas. indistintamente.

7 Ao longo do texto, gráficos, esquemas padrão, padrões de regência são utilizados 
movimento de 4 tempos, isto equivale a dizer que, a cada 1 segundo o próximo tempo é marcado, ou seja, todo padrão é realizado em 4 segundos. Analogamente, o mesmo padrão seria realizado em 2 segundos se a BPM fosse 120, já que cada tempo seria marcado a cada $1 / 2$ segundo. E os músicos atuais usam o metrônomo, como aparelho para medir o tempo desejado.

Durante a execução do padrão de regência o regente deverá estar atento à marcação de tempo, o qual realiza seguindo os batimentos por minuto abordados anteriormente, à medida que explora o espaço.

É importante mencionar que os padrões mostrados nos exemplos acima referem-se sempre ao movimento da mão direita. Desta forma, o movimento espelhado horizontalmente seria o equivalente à mão esquerda.

Considerando os dois padrões anteriores, vemos que há diferenças devidas ao fato de serem de escolas distintas, entretanto, outros fatores para escolha de variações entre os padrões têm características exclusivamente musicais, como expressividade, articulação rítmica (staccatos, legatos, etc), fraseado musical e afetividade, entre outros. Veja abaixo exemplos de alteração nos padrões de regência conforme o tipo de característica musical fornecido por autores:
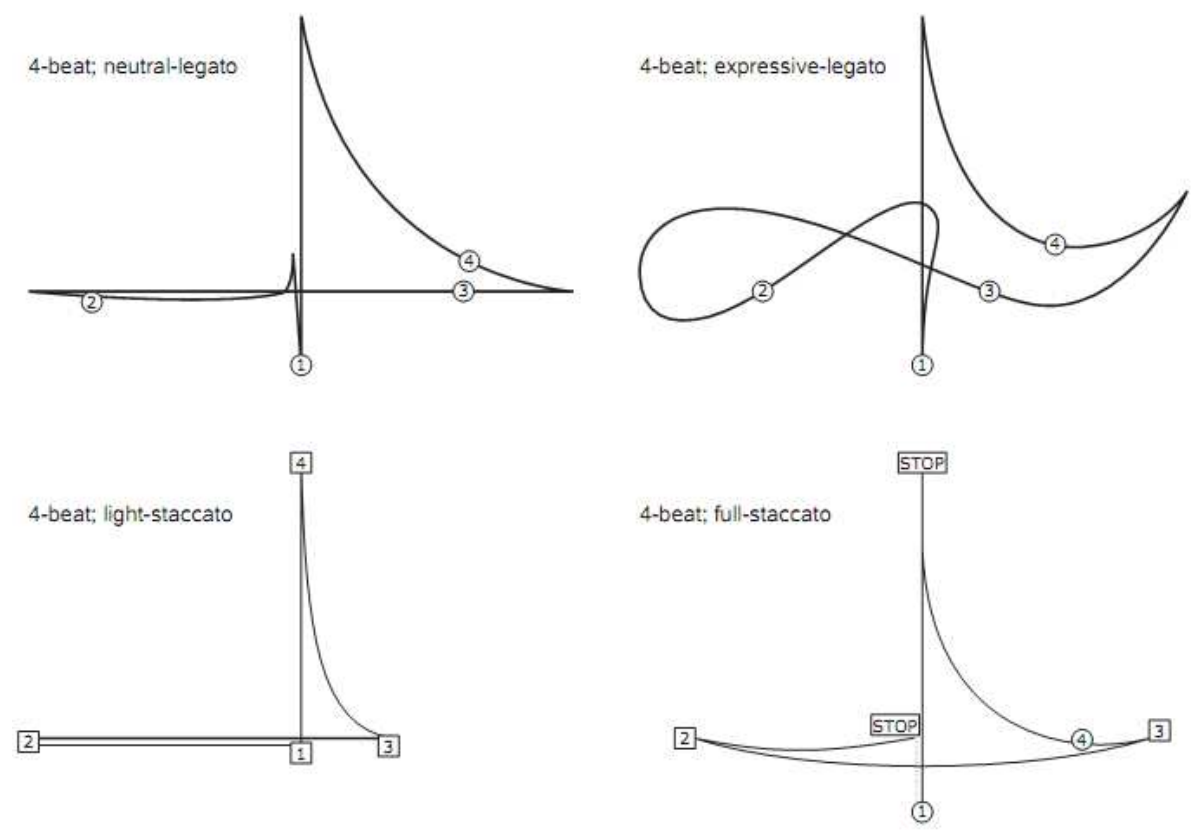

Figura 5 - Tempos quaternários em diversas articulações

Fonte: GRÜLL (2005). 
Embora as intenções musicais sejam diferentes entre si, a música é regida no mesmo padrão de quatro tempos por todos os padrões acima. Os padrões de regência ainda podem variar de acordo com marcações específicas na partitura, como: entradas, cortes, subdivisões, acentos e fermatas, entre outros conceitos musicais.

Com isso nota-se a complexidade da regência, principalmente no tocante da execução de gestos que deverão ser claros principalmente por poderem possuir sutis diferenças entre si. Isso dito, a forma com que o ensino ocorre é importante para o regente iniciante, já que este precisa engajar-se em um criticismo objetivo, de modo que desenvolva independência e maturidade sobre seus gestos através da consciência corporal. Segundo, DECKER \& HERFORD (1988), o regente deverá desenvolver sua própria característica dentro dos moldes e conceitos da regência.

O software desenvolvido compara em tempo real os gestos realizados pelo usuário com padrões previamente definidos no próprio software o quais serão vinculados a uma prática de regência também configurada. Com isso, será possível obter uma nota baseada na diferença entre o gesto realizado e esperado através da comparação de distâncias euclidianas.

\subsubsection{Planos de Regência}

Um dos parâmetros da regência são os planos espaciais sobre os quais ela se desenvolve. As mãos e os braços do regente sobem e descem sobre planos verticais, se afastam para os lados ou se reaproximam nos planos horizontais, e se encaminham para a frente ou voltam em direção ao corpo nos planos frontais. 

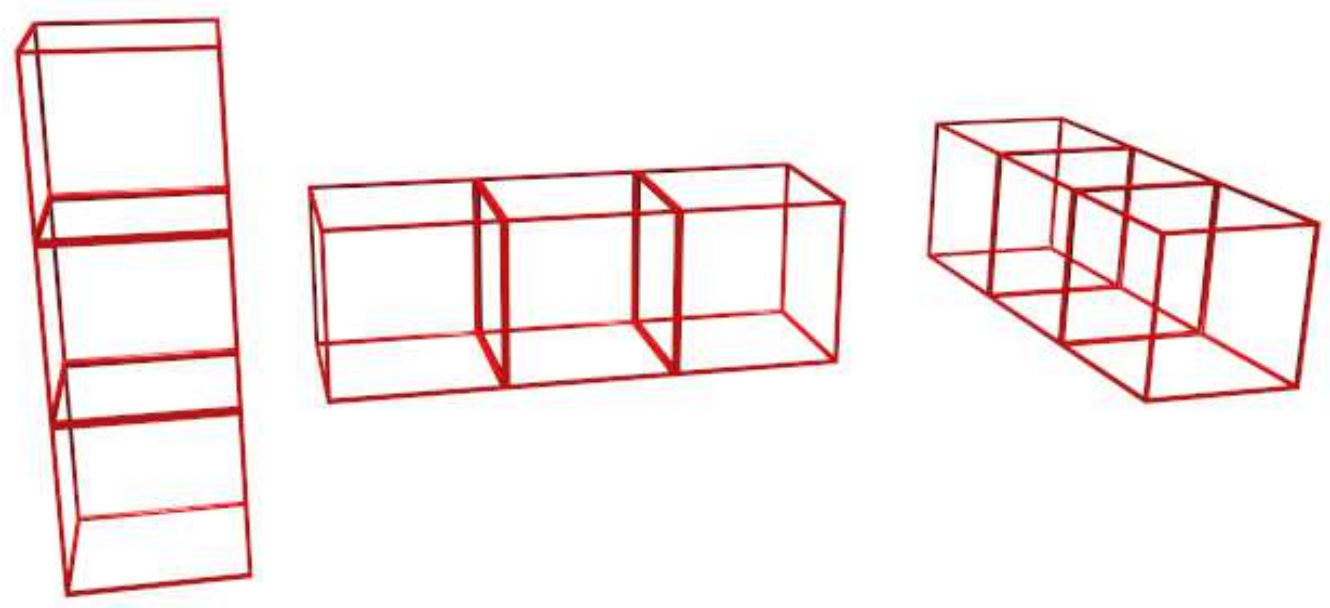

Figura 6 - Os diferentes planos de regência.

ANDERSON (s.d) propõe um método chamado "Técnica da Caixa", onde ele assume que há quadrados circunscritos centralizados em cada mão. Neste método, o regente utiliza (i) somente o dedo indicador para se movimentar no quadrado menor ou; (ii) somente o pulso para se movimentar no quadrado posterior ou; (iii) somente a mão e o antebraço no quadrado seguinte ou; (iv) todo o braço, incluindo cotovelos, para se movimentar pelo quadrado maior e mais externo.

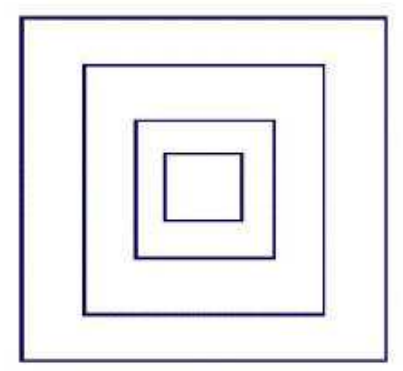

Figura 7 - Técnica da Caixa.

Fonte: ANDERSON, s.d.

Além dos movimentos realizados nos eixos x e y, como ilustrado anteriormente, o gesto poderá ser executado em diferentes variações de profundidade, neste respectivo plano. Isto é ilustrado por GMCCB (s.d) e representado pela figura abaixo: 


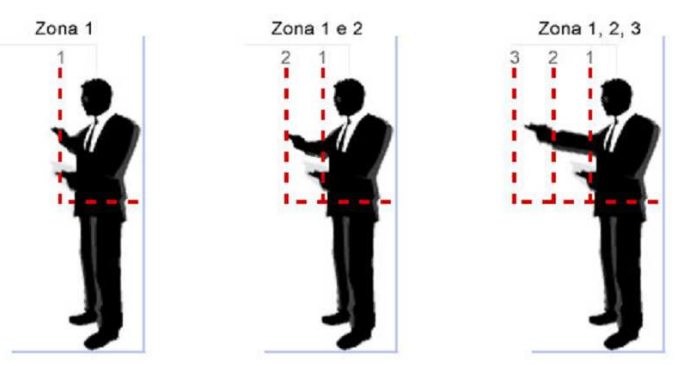

Figura 8 - Zonas de profundidade.

Fonte: GMCCB (s.d).

RAMOS (2011) consolida os conceitos acima e cria um cubo (Cubo de Ramos) o qual o regente pode explorar com seus gestos. Este cubo compreende os três já citados planos, é centralizado na coluna do regente:
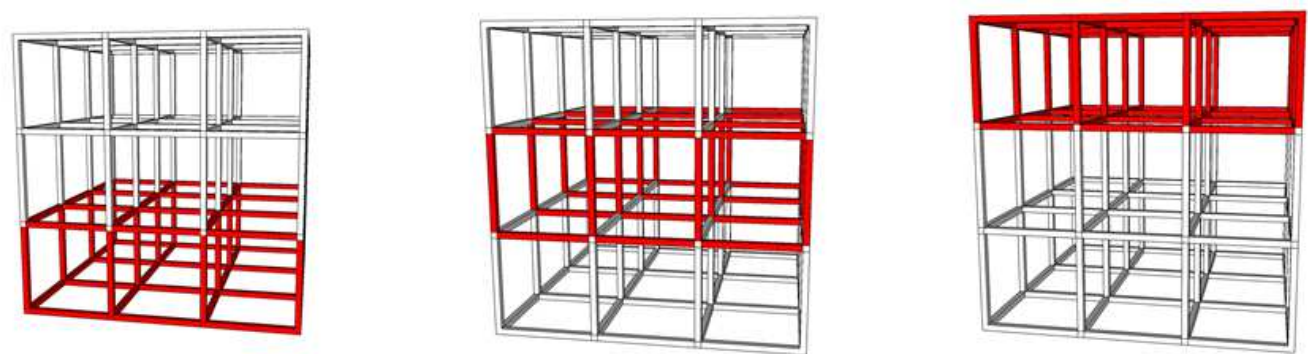

Figura 9 - As diferentes alturas no cubo de RAMOS (2011).

Fonte: RAMOS (2011).
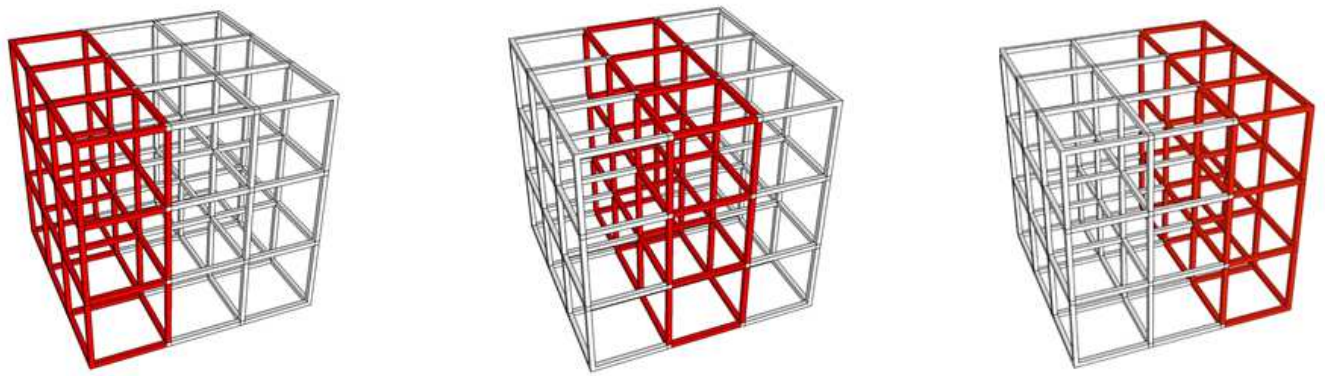

Figura 10 - As diferentes larguras no cubo de RAMOS (2011).

Fonte: RAMOS (2011).
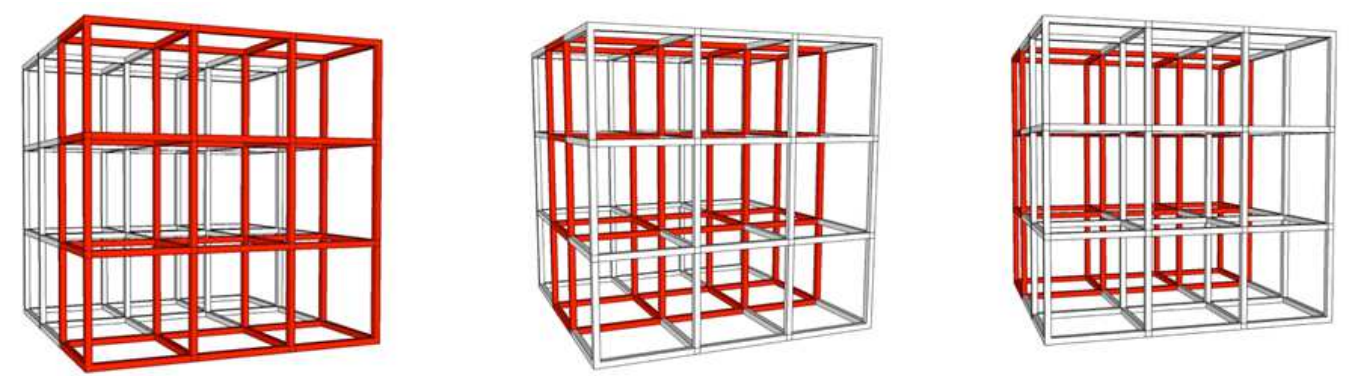

Figura 11 - As diferentes profundidades no cubo de RAMOS (2011).

Fonte: RAMOS (2011). 
O cubo é composto por cubos menores que podem ser explorados individualmente de acordo com a amplitude e direcionamento do gesto. As figuras abaixo mostram como o cubo se alinha com o corpo do regente:

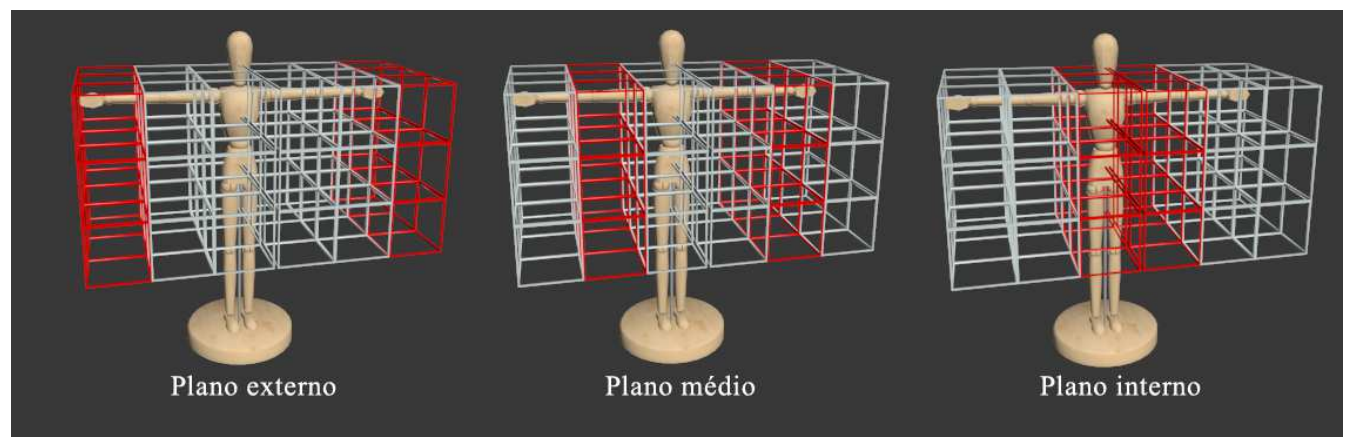

Figura 12 - Fatias do Plano Horizontal.

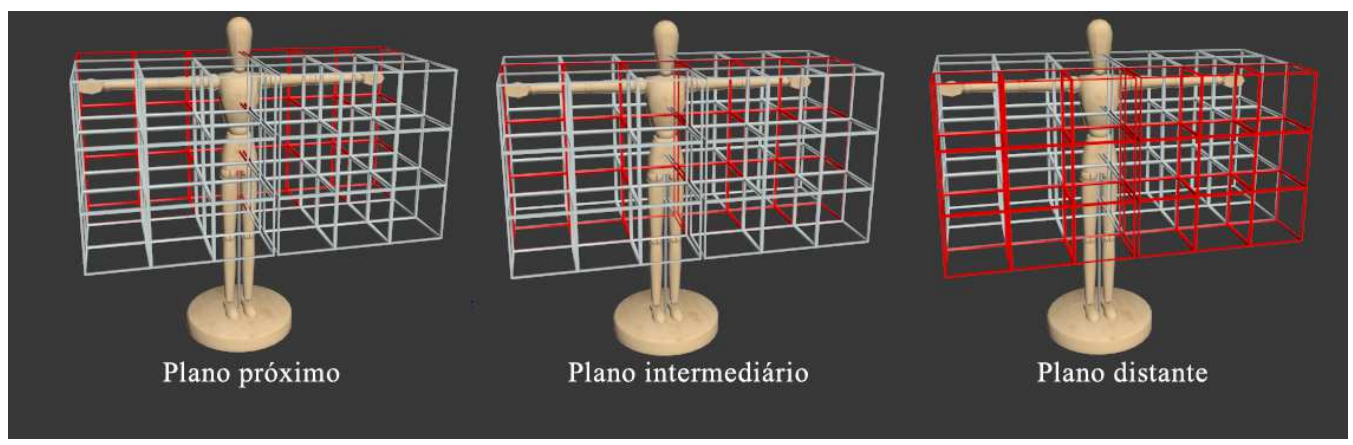

Figura 13 - Fatias dos Plano de Profundidade.

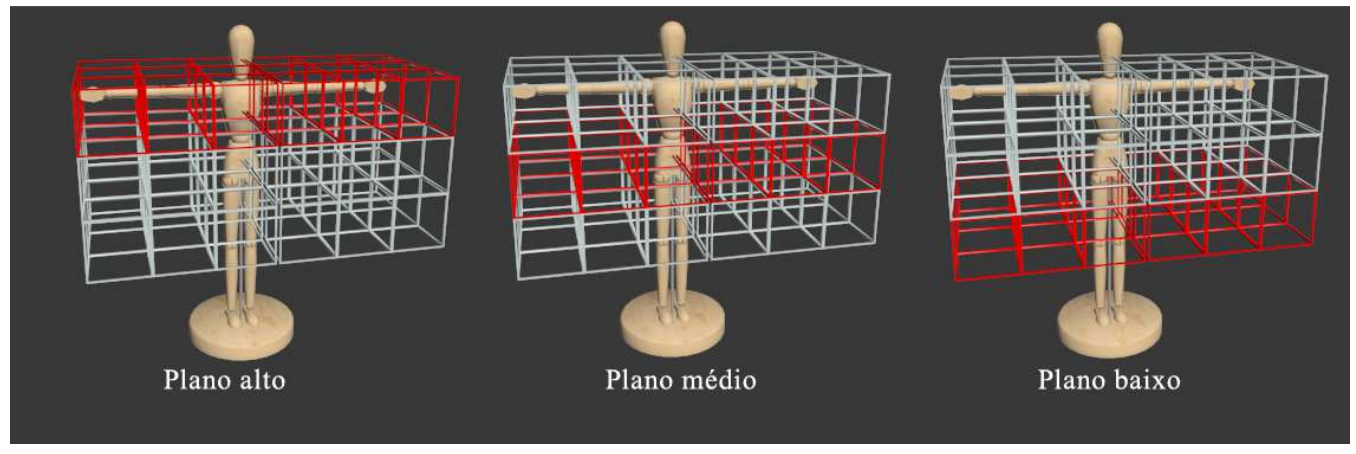

Figura 14 - Fatias do Plano Vertical.

Como normalmente o coro está colocado acima do regente. Este dado, aliado à necessidade óbvia de que o gesto do regente seja visto por todos os coralistas, aponta na altura respectiva do plano vertical.

RAMOS (2011b) declara que as principais funções do cubo são consciência corporal e treinamento da referência espacial. Este jamais deverá ser interpretado como uma "gaiola", ou algo que impõe limites à expressão artística do regente. 
Para o presente trabalho, propõe-se também que tais cubos sejam vistos pelo usuário à medida que este realiza seus gestos no software. E assim, qualquer um dos sub-cubos que interseccione qualquer uma das mãos do regente seria destacado em uma coloração diferente, de modo que ele saiba em quais regiões dos planos suas mãos se encontram.

\subsection{Visão Computacional}

\subsubsection{Introdução}

A visão computacional utiliza a computação para solucionar problemas que dependem de decisões tomadas a partir de dados obtidos pela visão pelo uso de sensores (e.g. câmeras, webcams, scanners, etc).

Segundo SHAPIRO \& STOCKMAN (2000): “o objetivo da visão computacional é realizar decisões úteis sobre objetos e cenas físicas reais baseadas em imagens capturadas".

Conforme PEDRINI \& SCHWARTZ (2008), os algoritmos de visão computacional utilizam imagens computacionalmente legíveis (isto é, imagens digitais capturadas por algum sensor ou criadas virtualmente) como dado a ser analisado para obter uma determinada saída (resposta). Segundo CORMEN et al. (2001) um algoritmo também pode ser entendido como um qualquer procedimento computacional bem definido que recebe algum valor (ou um conjunto de valores) como entrada e produz algum valor (ou conjunto de valores) como saída. Um algoritmo portanto é uma sequência de passos (instruções lógicas) computacionais, dispostas em um determinada ordem, e que necessariamente nesta disposição transformam a entrada em uma saída, resolvendo um determinado problema computacional.

\subsubsection{Sobre o Kinect}

O software proposto utiliza o Kinect como sensor para capturar a posição das juntas corporais do usuário no espaço tridimensional e após isso trabalha com tais dados para exibir informações úteis na tela. A vantagem do uso do Kinect é que ele 
não só captura os dados, mas também os dispõe em uma estrutura de dados ${ }^{8}$ de fácil navegação. Por exemplo, cada junta corporal detectada pelo Kinect é disposta em uma estrutura de dados chamada "esqueleto", onde todas juntas são relacionadas entre si e cada uma possui informações espaciais como posicionamento e rotação.

É importante citar que o Kinect é o sensor com maior custo benefício e fácil aquisição existente no mercado, tornando assim um fator importante a ser considerado na distribuição do software proposto. A Microsoft criou um sistema de reconhecimento de poses a partir de informações sobre imagens (features ${ }^{9}$ ) e seus respectivos dados de profundidade, estes últimos obtidos através de um feixe de raio infravermelhos disparados no ambiente e analisados em tempo real a partir do kinect, mapeando o relevo do ambiente (SANDBERG et al, 2011).

Com descritores extraídos de uma série de imagens, é possível realizar diversas classificações em cenas, e com isso descobrir se o objeto a ser encontrado encontra-se em cena ou não. Por exemplo, pode-se ter uma base de descritores de posturas humanas e sempre buscá-las em cena a partir da análise de imagens.

O Kinect cria modelos probabilísticos de rotulamento (labeling) a partir das partes do corpo de uma pessoa e assim infere as possíveis juntas corporais. Para isso, quando foi desenvolvido, o Kinect foi treinado com aproximadamente 500.000 imagens de diversas posturas corporais obtidas através de dispositivos de captura de movimentos (motion capture), cobrindo a maior parte dos movimentos que os usuários usualmente podem realizar, gerando uma imensa base de features. Além disso, como a quantidade de posturas que uma pessoa pode realizar é extremamente alta, um classificador de partes corporais foi desenvolvido para generalizar algumas das poses que não estão na base de imagens, potencializando ainda mais o dispositivo.

Para se ter uma idéia, ao total foram utilizadas 31 partes corporais em conjunto com features de profundidade para saber se um braço está à frente ou ao lado do corpo. Este método, desenvolvido por SHOTTON et al. (2011), se provou de alta qualidade e

\footnotetext{
${ }^{8}$ Uma estrutura de dados é um contêiner lógico que armazena um conjunto de variáveis que juntas buscam contribuir para a resolução de um ou mais algoritmos de forma eficiente (CORMEN et al. 2001).

${ }^{9}$ Features são descritores (características) extraídos a partir de uma ou mais imagens, utilizando um algoritmo específico, e que servem para inferir algo sobre a(s) mesma(s) (SHAPIRO \& STOCKMAN, 2000).
} 
pode-se dizer que é o estado da arte no que diz respeito a reconhecimento de posturas corporais humanas em tempo real atualmente.

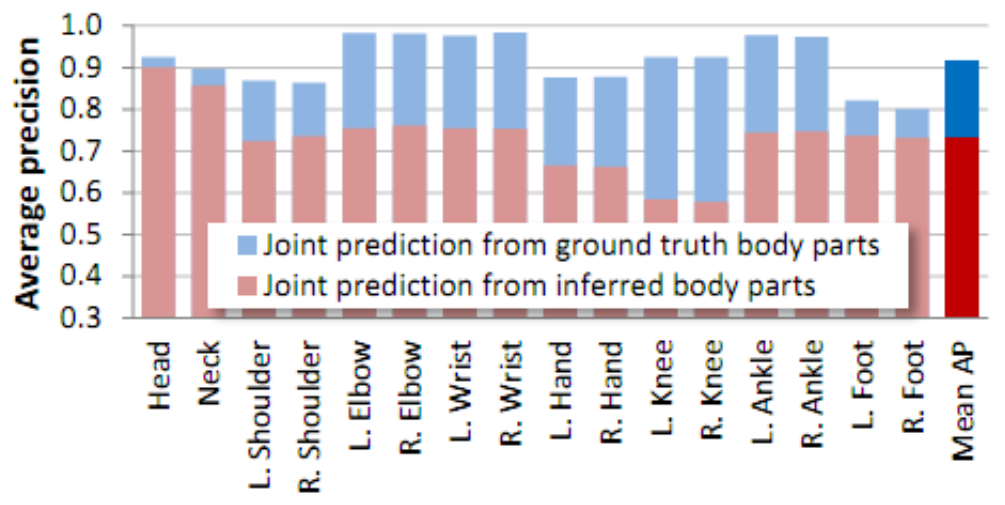

Figura 15 - Precisão média comparando predição de juntas através de juntas inferidas e juntas extraída a partir dos mapeamentos verdadeiros.

Fonte: SHOTTON et al. (2011).

Outra vantagem do uso do Kinect é o fato deste dispositivo não requerer: (i) o uso de marcadores ${ }^{10}$ no usuário em cena; (ii) técnicas complexas de calibragem de dispositivos - como no caso de diversas câmeras posicionadas em um ambiente, focando distintos ângulos e; (iii) pós-processamentos após a captura da imagem, já que os dados das juntas são providos automaticamente.

\subsubsection{Kit de Desenvolvimento}

Quando uma organização lança um dispositivo no mercado, junto deste dispositivo geralmente é fornecido um kit de desenvolvimento (SDK - do inglês Software Development Kit), que pode ser compreendido como um conjunto de funcionalidades acessíveis por qualquer software compatível com os requisitos mínimos do $S D K$ em questão.

Existem vários kits de desenvolvimento que podem ser utilizados para fazer uso das funcionalidades do Kinect, entretanto o mais evoluído, e que foi utilizado no software proposto, é o SDK criado pela própria Microsoft, atualmente em sua versão 1.7. Algumas das características deste seguem abaixo:

${ }^{10}$ Marcadores são identificadores dispostos num determinado alvo (cena, pessoa ou objeto), de modo que tal alvo possa ser monitorado de maneira mais fácil pelo sensor utilizado. Geralmente isto ocorre quando é necessário superar obstáculos técnicos, onde a detecção sem marcadores seria muito custosa. 
- Detecção completa do esqueleto do usuário, mapeando 19 juntas corporais;

- Não necessita de pose de calibragem para detectar o usuário em cena;

- Documentação das funcionalidades bem detalhadas tecnicamente;

- Gratuito;

- Suporta conectividade nativa nas linguagens $\mathrm{C}++$ e $\mathrm{C \#}$.

Entretanto, as principais limitações deste $S D K$ estão relacionados com o fato da Microsoft, por ser uma empresa privada, promover a difusão de seu sistema operacional principal, portanto:

- Está disponível somente para máquinas com sistema operacional Windows 7 ou superior;

- O código fonte não é disponibilizado.

Contudo, para os propósitos do software, ele segue sendo a melhor escolha para realizar o desenvolvimento. 


\section{Capítulo 3: Estado da Arte}

Recentes artigos retratam excelentes resultados no uso do Kinect para a obtenção de mapas de profundidade, inclusive ele está sendo utilizado para reconstruir ambientes tridimensionais em tempo real, já que o Kinect consegue fornecer toda esta informação a 30 quadros por segundo. NEWCOMBE et al. (2011) conseguiram excelentes resultados na reconstrução de cenas em tempo real através do Kinect.

VILLAROMAN et al. (2011) realizaram um estudo sobre as principais aplicações do Kinect para auxiliar estudantes nas aulas de interação homemcomputador (IHC), demonstrando as vantagens de se utilizar OpenNI e o NITE como SDK. SUMA et al. (2011) proprõem um middleware chamado FAAST o qual também utiliza os $S D K s$ anteriores para criar um servidor de streaming do esqueleto criado através dos dados fornecidos pelo Kinect, possibilitando vincular teclas do teclado ou do mouse, aos movimentos capturados. Com isso é possível utilizar gestos com softwares existentes, sem grande esforço de adaptação, além de possibilitar o controle remoto de aplicações via gestos transmitidos para aplicações remotas.

SUAY \& CHERNOVA (2011), utilizam o Kinect para mover robôs humanóides conforme as posturas que são realizadas por um humano mediante ao sensor do Kinect. OIKONOMIDIS et al. (2011) fazem uso das informações obtidas pelo Kinect para realizar o mapeamento das juntas dos dedos da mão de uma pessoa a 15 quadros por segundo.

No Brasil estudantes e entusiastas estão trabalhando em projetos comerciais que utilizam o Kinect. QUEIROZ (2011), por exemplo, desenvolveu um conversor de gestos do Kinect em eventos de tecla, fornecendo dados de entrada para um emulador de vídeo-game no computador, permitindo que o usuário jogue diversos jogos arcade antigos com o uso do Kinect. MATSUMURA \& SONNINO (2011) desenvolveram um aplicativo para visualização tridimensional de objetos utilizando o Kinect (suportado pelo Microsoft $S D K$ ) em conjunto com óculos que permitem visualizar o anaglifo e interagir com ele através de gestos. TOGORES (2011), faz uso do Kinect para extrair dados de movimentos realizados pelos usuários, extraindo vetores de características a 
serem utilizados em conjunto com técnicas de filtragem, quantização e o HMM (Hidden Markov Models) para tomar decisões e obter a classificação dos gestos realizados.

Ainda no Brasil e preocupando-se com a motivação dos alunos na educação, NUNES et al. (2011) sugerem que o uso da tecnologia na educação pode ser utilizada para obter diversas informações a serem utilizadas com propósito motivacional para o aluno. No que visa o Kinect, o método abordado analisa características corporais fisionômicas obtidas através deste sensor, obtendo assim informações emocionais e comportamentais dos expectadores perante algo que lhes é apresentado. A AGÊNCIA DETALHES (2011), lançou um software chamado Kinect Educação que utiliza o OpenNI e bibliotecas em Flash para criar jogos educacionais utilizando o Kinect. Por último, DA SILVEIRA (2011) utiliza o Microsoft Kinect SDK Beta para desenvolver uma aplicação que dispara comandos do teclado a partir do reconhecimento de gestos pré-definidos detectados à partir do ângulo formado por cada um dos cotovelos do usuário.

Se os métodos mais recentes aqui abordados forem comparados com métodos onde a tecnologia (Kinect) não estava disponível, como no caso de IRURTIA (2009), fica clara a dificuldade de realizar o mapeamento correto de juntas e posturas corretas. Portanto, acredita-se que houve um grande avanço nas aplicações com a chegada desta tecnologia.

\section{1 Ênfase na regência}

Em relação a aplicações similares ao que se deseja desenvolver nesta monografia, BRUEGGE et al. (2007) desenvolveram um aplicativo chamado Pinocchio. O foco deste aplicativo é desenvolver o gosto por música clássica em crianças. Para isto ele utiliza dispositivos como câmeras e o wiimote - controle remoto do video-game Nintendo Wii - para capturar dados do regente, controlando a orquestra em tempo real.

SCHMIDT et al. (2007) focam no uso de um outro dispositivo (relógio de pulso com sensores) chamado eWatch em conjunto com o aplicativo apresentado anteriormente por BRUEGGE et al. (2007), utilizando os dados retornados pelos sensores internos do eWatch (ver Figura 16 - eWatch. ao invés do uso do wiimote. 

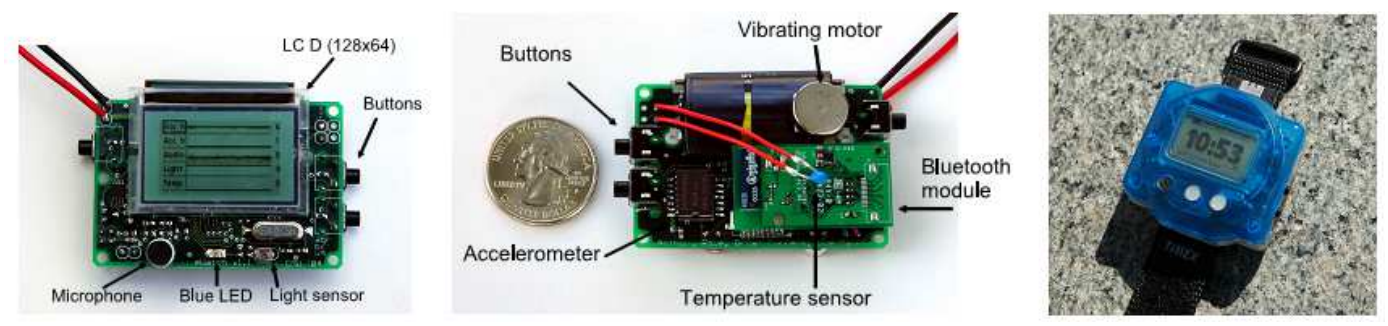

Figura 16 - eWatch.

Fonte: MAURER et al. (2006).

O projeto de SCHMIDT et al. (2007) analisa os dados do regente utilizando o eWatch paralelamente com uma filmagem em vídeo sincronizada com o clock do eWatch. Através dos dados capturados dos sensores, os padrões de regência são obtidos, e com estas informações, o áudio pré-gravado da orquestra é alterado. Inclusive através desta experimento pôde-se verificar que o regente, como esperado, rege cerca de alguns milisegundos à frente da orquestra, como na realidade. Ao final do artigo apresentado, os autores comentam que gostariam de construir um método independente de usuário e preciso no reconhecimento de gestos, que permitiria supervisionar gestos quaisquer de regência. Desta forma, acredita-se que o trabalho presente seja de grande valia para esta área, além de partir de um desejo anterior de outros trabalhos.

Entre outros projetos estão o de LEE et al (2005) que analisa os movimentos de regentes comparando-os a movimentos de não-regentes. GARNETT \& BRECHT (1992) utilizam um método que utiliza uma batuta infravermelha e redes neurais para extrair os padrões de regência e com isso controlar uma orquestra virtual, influenciando seus sons.

FUJINAGA \& TOBEY (1996) utilizam um sistema com duas câmeras especiais integradas a um software, posicionadas à frente e ao lado do regente, que capturam seus movimentos através da análise de vídeo que captura os movimentos da batuta, traduzindo suas coordenadas tridimensionais para um software.

LEE et al. (2006) se baseia na tese de LEE et al (2005), GRÜLL (2005) e NAKRA (2000) para criar um sistema que monitora uma batuta desenvolvida especialmente para detecção de gestos de regência, de modo a realizar alterações em um vídeo e som de uma orquestra a partir dos gestos de regência. 
NAKRA (2000) discorre sobre o uso da jaqueta de regência desenvolvida por PICARD \& MARRIN (1998), utilizando-a para realizar tratamento de sinais advindos dos sensores da mesma. Esta jaqueta contém uma série de sensores utilizados para monitorar os movimentos da regência.

Por último, USA \& MOCHIDA (2006), apresentaram um método que identifica: (a) o início e o fim de uma regência, einsatz (corte de um cantor ou naipe), marcação de tempo, mudanças no tempo, o número do tempo sendo executado dentro de uma medida (padrão), fermatas, dinâmica da música, alguns aspectos da articulação musical (e.g. expressivo, staccato), respiração. O sistema reconhece os movimentos realizados pela mão direita e os interpreta através de HMM. Em seu trabalho, os autores também listam diversos outros autores que buscaram supervisionar o regente através de uso de diversos tipos de sensores. O ponto negativo do trabalho destes autores é que eles utilizam uma batuta com acelerômetros e não somente o corpo do regente para extrair as informações.

Em todos os artigos lidos, percebeu-se que houve certa dificuldade dos autores em conseguir realizar todas as atividades em tempo real, exceto por BRUEGGE et al. (2007), mas que este usou um aparato desconfortável para a regência. Portanto, acredita-se que o uso do Kinect permitirá dar o próximo passo nos softwares de regência, principalmente por permitir uma melhor análise em tempo real, sem que o regente tenha que usar dispositivos ou sensores desconfortáveis. Fica claro que a maioria dos trabalhos listados anteriormente foca no desenvolvimento de um software para influenciar um coro ou orquestra virtual a partir de informações extraídas do regente, mas nenhuma das aplicações foca na supervisão e no ensino da regência para o próprio regente, que é o escopo principal do presente trabalho. 


\section{Capítulo 4: Software para Ensino de Regência Coral}

\subsection{Abordagem}

Como citado na Seção 1.2, o estudante de regência precisa se familiarizar com os parâmetros da regência, seus padrões e planos (este último através do cubo de Ramos - ver Seção 2.1.5), aprimorando assim sua consciência corporal e a localização espacial e trazendo ao professor uma ferramenta para análise da evolução de seus alunos.

A partir da interação entre o laboratório Comunicantus da Escola de Comunicações e Artes desta Universidade e o Instituto de Matemática e Estatística, observou-se que tais objetivos descritos podem ser alcançados através do uso de tecnologias existentes, tais como o Kinect.

Assim, após uma série de reuniões com o regente responsável, Prof. Dr. Marco Antonio da Silva Ramos, delimitou-se o escopo do software proposto através de funcionalidades as quais foram listadas ao longo deste capítulo.

As principais fontes de conhecimento sobre regência coral aqui utilizadas foram: (i) notas de aula e material fornecido durante a disciplina "Análise Musical para Performance: Interfaces entre Criação e Interpretação a Partir do Universo Coral (Escola de Comunicações e Artes - Universidade de São Paulo)”, (ii) referências bibliográficas fornecidas pelo regente responsável citado acima e (iii) pesquisas nos acervos digitais de regência coral de diversas universidades os quais estão disponíveis na Internet. Todas as referências podem ser encontradas no Capítulo 6: do presente documento.

Durante a fase de desenvolvimento, o software foi aprimorado através de diversas reuniões com o regente supracitado. Nestes encontros o protótipo da aplicação era demonstrado e testado. Também durante tais reuniões, os requisitos eram detalhados, esclarecidos e novas referências bibliográficas eram fornecidas. Alguns dos encontros foram utilizados para revisar o presente documento, garantindo que a 
linguagem utilizada pudesse ser compreendida por leitores das diversas áreas envolvidas, já que este se trata de um trabalho multidisciplinar.

\subsection{Público-alvo}

Para utilizar o software o usuário deverá ter o conhecimento mínimo sobre técnicas de regência coral (padrões de regência) e teoria musical (compassos, tempos musicais, etc). Portanto, o principal público-alvo seria composto por:

- Estudantes de regência coral (graduação, pós-graduação);

- Professores de regência coral.

\subsection{Descrição Funcional}

O software foi organizado em três grandes módulos tratanto os principais aspectos do ensino da regência coral:

1. Editor de Padrões de Regência (Biblioteca de Padrões);

2. Editor de Práticas de Regência;

3. Visualizador (Podium) do Regente.

Em (1) os padrões de regência podem ser criados conforme explicação descrita na Seção 2.1.4 (Padrões de Regência). Algumas das principais funcionalidades deste módulo são:

1. Permitir a criação de formas geométricas onde cada uma represente um padrão de regência (como os ilustrados nas Figuras da Seção 2.1.4);

2. Possibilidade de adicionar, remover e movimentar pontos de controle da curva que representa o padrão de regência;

3. Possibilidade de adicionar, remover e movimentar marcações de tempo (tempos) no padrão de regência;

4. Permitir a detecção automática dos tempos no padrão de regência, agilizando a criação do mesmo, caso o usuário deseje;

5. Possibilidade de alinhar automaticamente os pontos de controle à grade, facilitando a criação precisa e simétrica do padrão de regência;

6. Permitir o fechamento automático da curva;

7. Exibir, salvar, excluir ou modificar um padrão de regência. 
Tais funcionalidades podem ser vistas na Figura 17 abaixo e são identificadas pelos balões informativos dispostos na mesma.

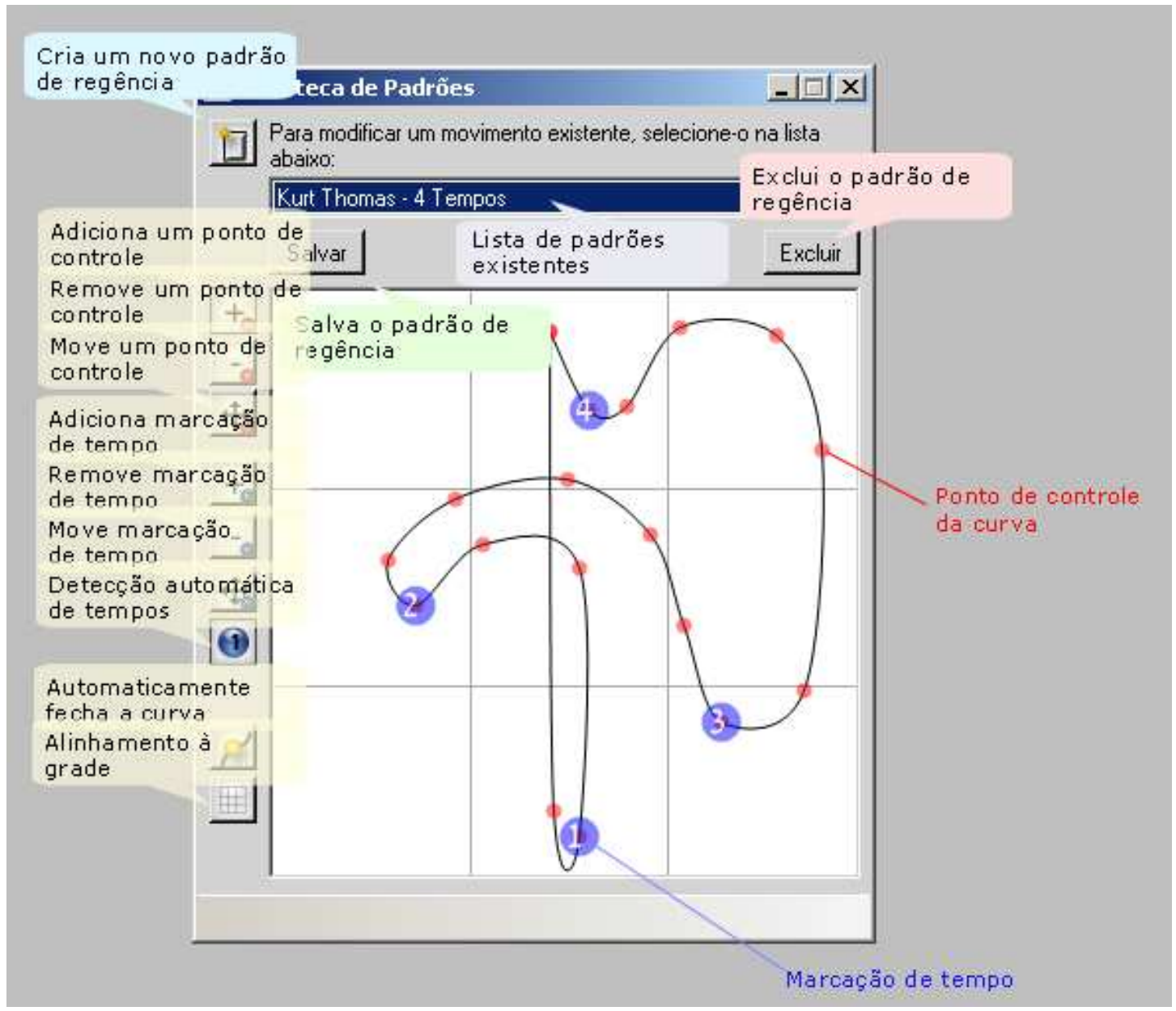

Figura 17 - Editor de Padrões de Regência (Biblioteca de Padrões).

Em (2) é possível definir sequências, envolvendo os padrões de regência previamente criados em (1), associando-as às mãos do regente, definindo assim o conceito de prática sintética. Isto engloba:

- Criar uma pré-seleção dos padrões de regência que serão utilizados pela prática sintética (Figura 18 abaixo); 


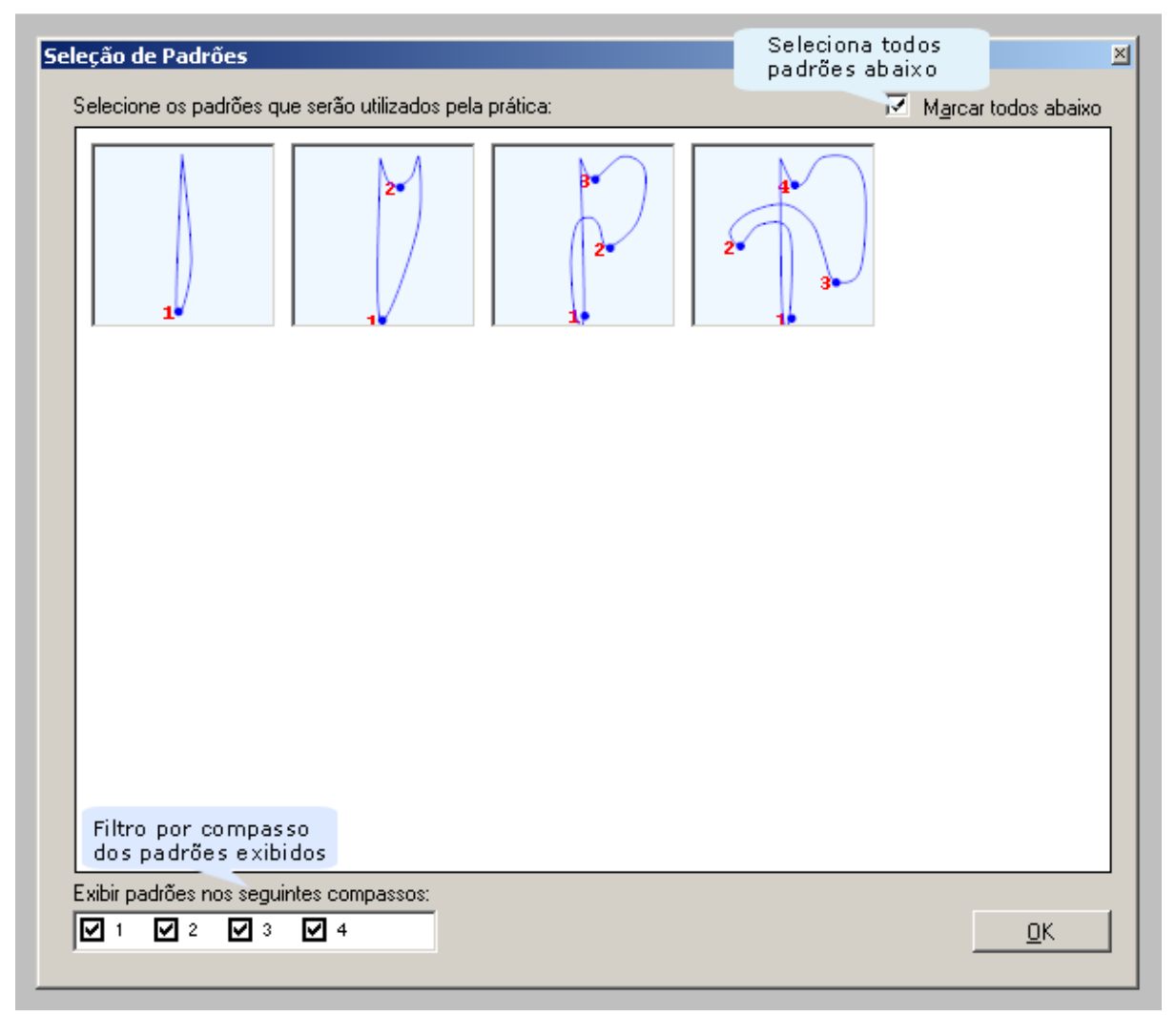

Figura 18 - Pré-seleção de padrões de regência definidos em (1).

- Selecionar um dentre os padrões pré-selecionados anteriormente, vinculando-o a uma das mãos do regente e informando em quais subcubos e em qual profundidade tal padrão será realizado. Esta configuração é denominada sequência e representa o movimento a ser realizado pelas mãos do regente durante a execução da prática sintética.

- Adicionar, modificar ou excluir uma ou mais sequências;

- Possibilidade de definir o valor do parâmetro "batidas por minuto" a ser utilizado por uma determinada sequência;

- Salvar, modificar ou excluir práticas sintéticas.

Tais funcionalidades podem ser vistas na Figura 19 abaixo e são identificadas pelos balões informativos dispostos na mesma. 


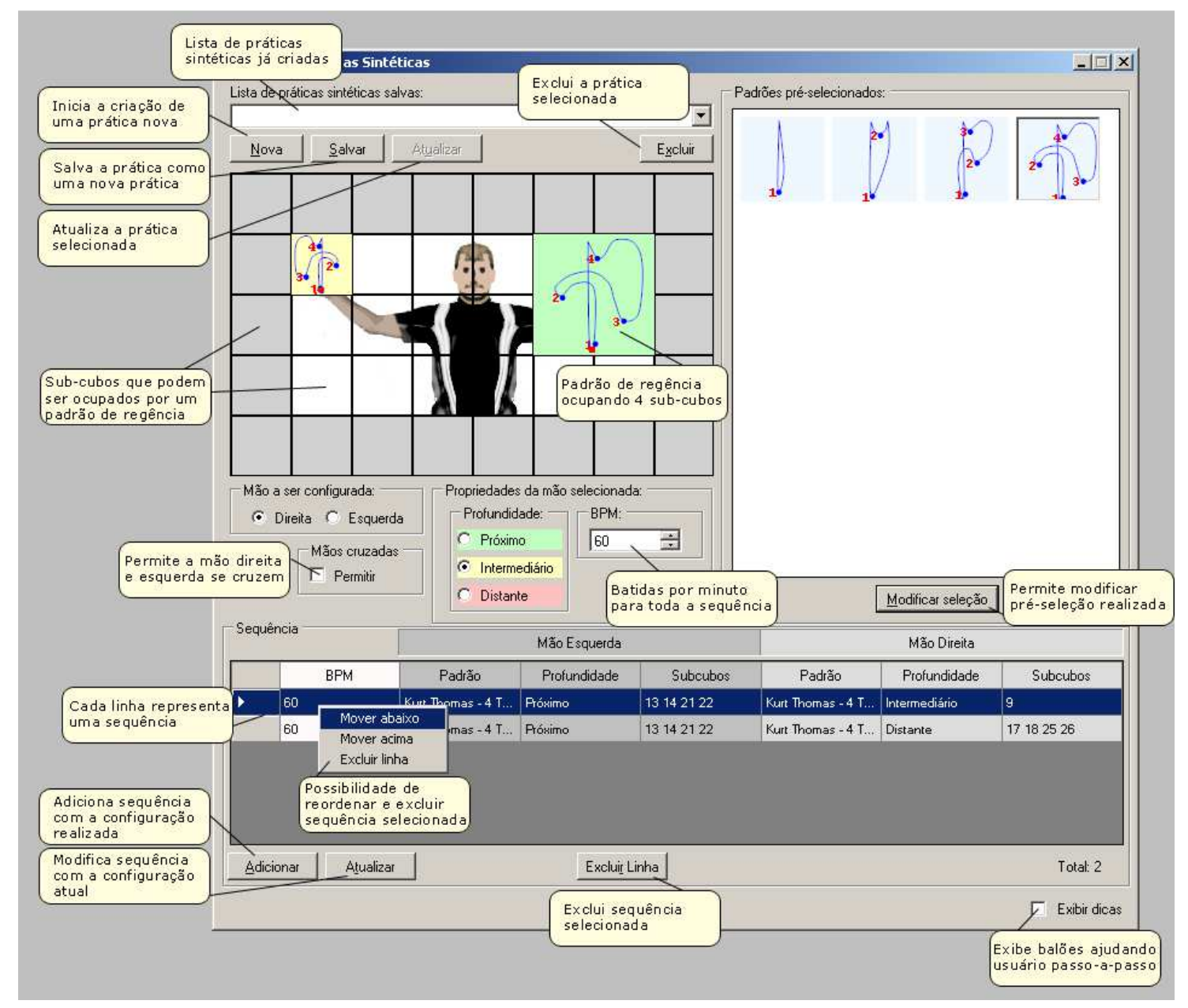

Figura 19 - Editor de Práticas Sintéticas

Além da possibilidade de criar práticas sintéticas, é possível criar práticas através de gravações. Isto é, um regente realiza movimentos por um determinado tempo em frente ao sensor que é responsável pela captura dos mesmos. Após isso, os dados são armazenados em uma estrutura de prática o qual poderá ser utilizada futuramente por outro regente o qual poderá tentar copiar os movimentos gravados. Este tipo de prática é conhecido como prática gravada. O editor utilizado para gerenciá-las (gravar, atualizar ou excluir) pode ser visto na Figura 20 abaixo: 


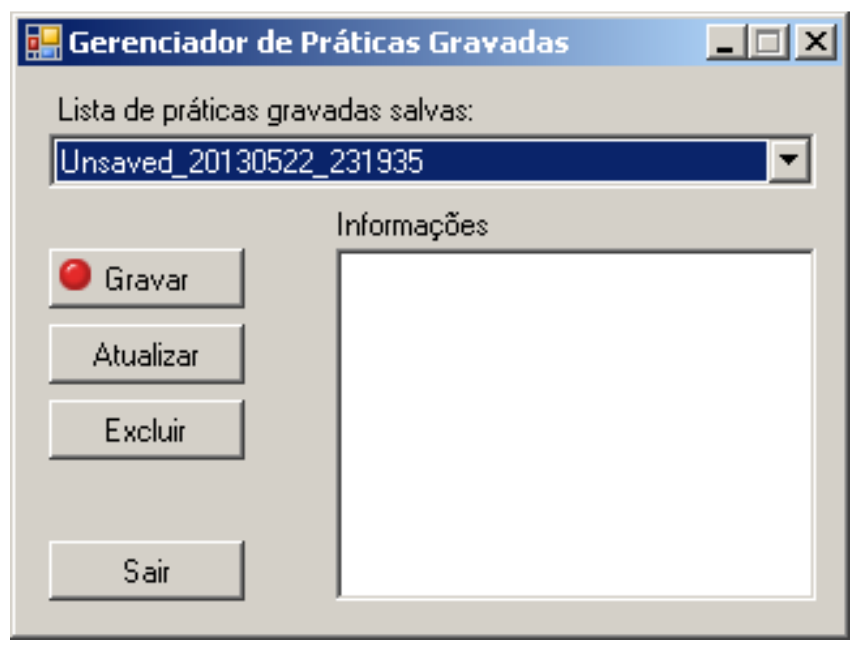

Figura 20 - Gerenciador de Práticas Gravadas

Em (3) é possível:

- Visualizar (replay) os movimentos de uma ou mais práticas, sejam estas sintéticas ou gravadas. Sendo que, no caso de práticas sintéticas, a visualização é dada com base nos padrões de regência associados às mãos do regente e as quais foram dispostas em sequências pertencentes à pratica em questão. Para práticas gravadas, a exibição é feita com base nas coordenadas tridimensionais capturas pelo sensor;

- Pausar o replay a qualquer momento, podendo retomá-lo quando desejado;

- Realizar treinamentos, em tempo-real, com base em práticas anteriormente criadas. Neste caso uma nota é dada ao usuário ao término do treinamento com base no movimento realizado. Isto é feito da análise de distâncias Euclidianas;

- Rotacionar a câmera em volta da cena, podendo visualizar a cena por qualquer ângulo, assim como aproximar ou distanciar a câmera (zoom) para uma análise mais precisa dos movimentos;

- Ocultar ou exibir elementos extras (detalhes) em cena;

- Exibição do Cubo de Ramos - ver Seção 2.1.5 o qual alinhar-se-á à coluna do usuário e inclusive rotacionará conforme a coluna é rotacionada;

- Detectar intersecção das mãos do usuário com os sub-cubos 
pertencentes ao Cubo de Ramos, colorindo-os de maneira diferenciada, permitindo distinção da profundidade a qual a mão se encontra;

- Caso a prática utilizada como base para o treinamento seja uma prática sintética, permitir escutar marcações de tempo conforme as BPM definidas anteriormente em (2), atuando como metrônomo.

\subsection{Implementação}

As tecnologias utilizadas durante o desenvolvimento foram a linguagem C\#, o SDK da Microsoft para o Kinect, o Microsoft XNA (bibliotecas 3D, similar ao DirectX e OpenGL) e modelagem 3D realizada utilizando o 3DS MAX.

\subsection{Principais Algoritmos}

\subsubsection{Interpolação de Pontos de Controle para Gerar Padrão de Regência}

De acordo com o que foi apresentado na Seção 4.3, a Biblioteca de Padrões provê uma interface gráfica para que o usuário adicione os pontos de controle que, após interpolados, formarão a curva a qual resultará no padrão de regência final.

Uma função de interpolação de pontos é capaz de gerar uma nova sequência de pontos a partir de outra já conhecida. As formas mais comuns de interpolação de pontos são: (a) linear; (b) polinomial; e (c) por spline (BOURKE, 1999).

O método aqui abordado e que foi utilizado na implementação do software, é o Catmull-Rom (CATMULL \& ROM, 1974), um método por spline. Inicialmente este método foi desenvolvido para computação gráfica, seu uso inicial era para desenhar superfícies e curvas, mas posteriormente seu uso se expandiu para outros própositos (JOY, 2002).

O algoritmo pode ser descrito da seguinte maneira:

Seja $P=\left[p_{1}, p_{2}, p_{3}, \ldots, p_{n}\right] \subseteq \mathbb{R}^{2}$ uma sequência dos pontos de controle pertencentes ao padrão de regência e para cada ponto $p_{i} \in P$, seja $G_{i}=\left(p_{i_{1}}, p_{i_{2}}, p_{i_{3}}, p_{i_{4}}\right) \in P^{4}$, tal que:

- $i_{1}=\max \{1, i-1\}$;

- $i_{2}=i$;

- $i_{3}=\min \{n, i+1\}$; 
- $i_{4}=\min \{n, i+2\}$

Por exemplo, se $n=20$, então $G_{1}=\left(p_{1}, p_{1}, p_{2}, p_{3}\right)$ e $G_{20}=$ $\left(p_{19}, p_{20}, p_{20}, p_{20}\right)$.

Seja $q \in \mathbb{N}_{+}$, o número de pontos que se deseja interpolar entre $p_{i} \in P$ e $p_{((i \bmod (n))+1)}$, denotamos o conjunto $Q \subseteq \mathbb{R}$ da seguinte forma:

$$
Q=\left\{0, \frac{1}{q}, \frac{2}{q}, \ldots, \frac{q}{q}=1\right\}
$$

Para cada ponto $p_{i} \in P$, definimos a função $f_{i}: Q \rightarrow \mathbb{R}^{2}$, da seguinte maneira:

$$
f_{i}(x)=T(x) \cdot M \cdot G_{i}^{t}
$$

onde:

- $T(x)=\left(1, x, x^{2}, x^{3}\right) \in \mathbb{R}^{4}$;

- $M=\frac{1}{2}\left[\begin{array}{cccc}0 & 2 & 0 & 0 \\ -1 & 0 & 1 & 0 \\ 2 & -5 & 4 & -1 \\ -1 & 3 & -3 & 1\end{array}\right]$;

- $G_{i}^{t}=\left(\begin{array}{l}p_{i_{1}} \\ p_{i_{2}} \\ p_{i_{3}} \\ p_{i_{4}}\end{array}\right)$

Como pode ser visto em (1), o resultado de cada $f_{i}(x)$ é uma função cúbica em $x$ com as seguintes propriedades:

a) A spline passa por todos os pontos de controle;

b) A spline não possui descontinuidades na direção da tangente e de sua magnitude.

A propriedade (a) citada acima é a principal característica de Catmull-Rom splines. Além disso, a movimentação de um único ponto de controle afetará a curva localmente. Para o presente trabalho isto é desejável pois permite que o usuário ajuste precisamente o posicionamento do ponto de controle, sem afetar a curva como um todo, criando padrões de regência com maior precisão.

\subsubsection{Escala e Rotação Horizontal dos Padrões de Regência}

Os padrões de regência, criados na Biblioteca de Padrões, são utilizados pelo Editor de Práticas Sintéticas durante a criação de uma prática, onde são dimensionados conforme seleção realizada pelo usuário no cubo do regente. 

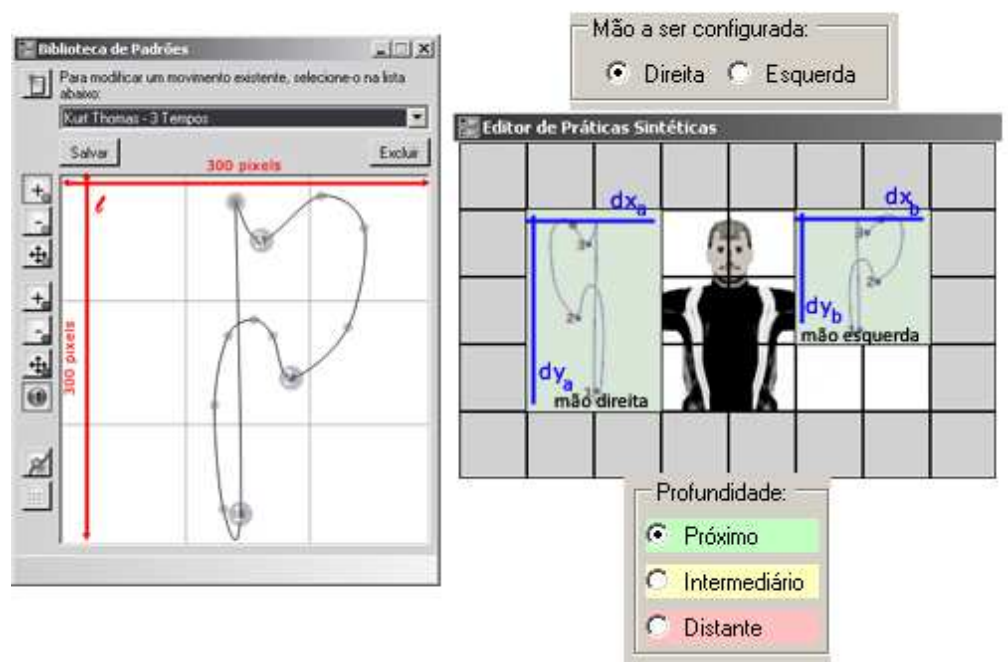

Figura 21 - Escala entre padrão original e padrão redimensionado pelo usuário.

Um padrão poderá ser associado a uma ou ambas as mãos do regente. Quando a mão configurada for a esquerda, não só devemos aplicar uma escala ao padrão com base nas dimensões da janela a qual este encontra, mas também devemos reflexioná-lo horizontalmente, criando o movimento oposto equivalente. Isto ocorre porque durante o treinamento, o Kinect, o qual estará posicionado à frente do usuário, também capturará as coordenadas do estudante de maneira reflexionada, tornando necessário utilizar o mesmo sistema de coordenadas.

Portanto, é necessário determinar uma escala com base nas dimensões da janela do padrão (e.g. $d_{x}$ e $d_{y}$ ), no tamanho da janela de criação do padrão (e.g. $l$ ), a qual é um quadrado, e na mão escolhida (esquerda ou direita), aplicando tal escala sobre todos os pontos do padrão original.

Seja $d_{x} \in \mathbb{N}^{*}$ tal que $d_{x}$ é a largura da janela de seleção definida pelo usuário no Editor de Práticas Sintéticas e seja $d_{y} \in \mathbb{N}^{*}$ tal que $d_{y}$ é a altura da janela de seleção definida pelo usuário no Editor de Práticas Sintéticas, ambas determinadas para um mesmo padrão de regência; $l \in \mathbb{N}^{*}$, tal que $l$ é constante e representa o lado da janela utilizada na criação do padrão de regência pela Biblioteca de Padrões (e.g. 300); e: $m \in\{-1,1\}$ tal que $m=\left\{\begin{array}{c}-1 \text {, se padrão pertence à mão esquerda } \\ 1 \text {, se padrão pertence à mão direita }\end{array}\right.$;

Podemos encontrar as escalas a serem aplicadas nos pontos do padrão de regência para os eixos $x$ e $y$ através das seguintes definições, considerando a operação $\lfloor v\rfloor$ como o maior inteiro não maior que $v$ (arredondamento para baixo): 
- $s_{x} \in \mathbb{Z}^{*}$ tal que $s_{x}=\left\lfloor\frac{d_{x}}{l} \cdot m\right\rfloor$;

- $\quad s_{y} \in \mathbb{N}^{*}$ tal que $s_{y}=\left\lfloor\frac{d_{y}}{l}\right\rfloor$;

Sejam $P=\left[p_{1}, p_{2}, p_{3}, \ldots, p_{n}\right] \subseteq \mathbb{R}^{2}$ a sequência matemática de todos os pontos pertencentes ao padrão de regência e $P^{\prime}=\left(p_{1}^{\prime}, p_{2}^{\prime}, p_{3}^{\prime}, \ldots, p_{n}^{\prime}\right) \subseteq \mathbb{R}^{2}$ o padrão de regência gerado após $P$ receber a escala $S=\left[\begin{array}{cc}s_{x} & 0 \\ 0 & s_{y}\end{array}\right]$, resultando no padrão dimensionado pelo usuário, onde cada $p_{i}^{\prime} \in P^{\prime}$ é obtido pela função $g: P \rightarrow P^{\prime}$, definida da seguinte forma:

$$
p_{i}^{\prime}=g\left(p_{i}\right)=S \cdot p_{i} \in \mathbb{R}^{2}
$$

Vemos que através de $g$ é possível gerar variações nas dimensões de um único padrão conforme a configuração realizada pelo usuário.

\subsubsection{Geração da Prática Sintética}

O objetivo principal de uma prática sintética é gerar coordenadas tridimensionais a partir de uma configuração baseada em sequências ${ }^{11}$ de regência às quais possuem um ou dois padrões de regência associados, como pode ser visto no diagrama abaixo:

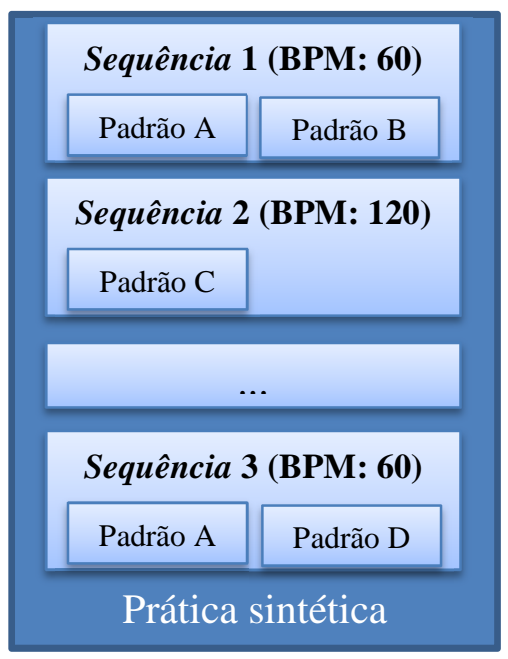

Figura 22 - Diagrama de uma prática sintética.

Estas coordenadas são armazenadas em um arquivo de prática e possibilitam ao estudante de regência realizar treinamentos para aprimorar seus gestos, já que seu

${ }^{11}$ Sequência neste contexto se refere à sequência da prática sintética e não a uma sequência matemática. Será utilizada em itálico para diferenciar-se de sequência matemática. 
movimento, o qual é capturado pelo Kinect, será comparado ao que foi produzido sintéticamente pelo algoritmo a ser descrito nesta seção. Gerar tais coordenadas sintéticas é uma tarefa que envolve:

1. Simular como um padrão qualquer seria executado normalmente por um humano (regente).

Se assumíssemos que a mão associada ao padrão de regência se movimenta com velocidade constante através do padrão de regência, por mais que a BPM informada no padrão e seus tempos sejam respeitados, estaríamos criando um movimento artificial e o qual seria replicado pelo usuário da aplicação durante o treinamento, levando o estudante a um movimento longe do real. Portanto, foi preciso encontrar uma função que distribuísse os pontos do padrão, respeitando o tempo informado no padrão e na BPM da sequência, para uma movimentação mais próxima da real.

DRISCOLL (1999) observou os movimentos executados por diversos regentes e verificou que o gráfico que tais movimentos produzem no eixo y é similar ao da função seno. Portanto, o algoritmo desenvolvido faz uso desta função a qual está diretamente associada à BPM da sequência a qual o padrão pertence e à quantidade de tempos do padrão.

2. Encadear uma sequência de padrões, isto é, cada um de seus dados, ao longo do tempo;

Como visto anteriormente, uma sequência possui uma determinada BPM, e poderá possuir um ou dois padrões de regência, cada qual associado unicamente a uma mão do regente. Cada padrão está associado a uma profundidade (próximo, médio ou distante). Assim, é preciso interpretar cada sequência configurada na prática, passando por cada um de seus padrões e gerando dados a partir do processo mencionado em (1).

3. Traduzir os padrões, até então exibidos bidimensionalmente, do espaço 2D para o 3D.

Até o momento, os padrões de regência foram utilizados no espaço bidimensional, entretanto, o usuário do sistema (e.g. estudante de regência) treinará no espaço tridimensional, e como desejamos medir a precisão do movimento nos três eixos $(x, y$ e $z)$ devemos definir um valor em $z$ para os pontos dos padrões informados nas sequências definidas através de um critério determinado.

Podemos entender que cada padrão de regência é utilizado pela aplicação como um vetor e que cada posição armazena uma coordenada bidimensional. Por exemplo: 


\begin{tabular}{|c|c|c|c|c|c|c|}
\hline Índices & & & 3 & & & 50 \\
\hline Pontos & $(3,4)$ & $(3,5)$ & $(3,6)$ & $\ldots$ & $(4,7)$ & $(5,8)$ \\
\hline Tempo & & & 1 & & & 2 \\
\hline
\end{tabular}

Figura 23 - Pontos e índices armazenados.

A figura acima ilustra um padrão de regência formado por $n$ pontos e que possui 2 tempos, os quais podem ser identificados nas posições 3 e 50 do vetor de Pontos. Isto é, nas coordenadas $(3,6)$ e $(5,8)$ temos o tempo 1 e 2 do padrão respectivamente. Estes índices para os pontos que marcam os tempos são armazenados no vetor de Índices que, conforme exemplo acima, possui dois elementos.

Trabalhar com índices torna possível saber quantos pontos existem entre dois tempos de um padrão através da subtração dos respectivos índices. Tomando como base o exemplo acima, há 47 pontos entre o tempo 1 e 2. Esta quantidade de pontos no intervalo pode ser interpretada como a distância a ser percorrida pelo tempo determinado conforme a BPM da sequência.

Sejam $P=\left[p_{1}, p_{2}, p_{3}, \ldots, p_{n}\right] \subseteq \mathbb{R}^{2}$ a sequência matemática dos pontos que compõem um padrão de regência e $B=\left\{b_{1}, b_{2}, b_{3}, \ldots, b_{m}\right\} \subseteq \mathbb{N}$ o conjunto dos índices em $P$ de forma que $p_{b_{i} \in B} \in P$ representa um ponto onde há marcação de tempo (beat). Observe que $m<n$, isto é $|P|<|B|$, já que existem mais pontos em um padrão de regência do que marcações de tempo associadas ao padrão, como pode ser visto abaixo:

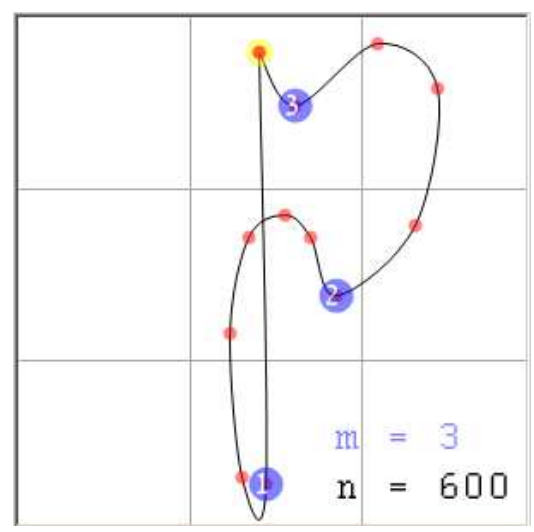

Figura 24 - Padrão de regência e os valores de m e n.

Por exemplo, considere o padrão logo acima o qual nomearemos $P$, este poderia ter um conjunto $B=\{279,324,502\}$ associado onde $p_{279}, p_{324}, p_{502}$ seriam pontos de marcação de tempo pertencentes a $P$. 
Considere agora uma sequência matemática de padrões $S=\left[P_{1}, \ldots, P_{o}\right]$ com $1 \leq o \leq 2$ representando uma sequência a qual poderá possuir um ou dois padrões associados e $c \in \mathbb{N}^{*}$ uma constante a qual representa a BPM associada a $S$. Isto é, em um padrão de uma sequência $S$ onde $c=60$, significa dizer que a cada $\frac{60}{c}=\frac{60}{60}=1$ segundo a distância parcial (distância entre duas marcações de tempo) deste padrão deverá ser percorrida - a exemplo disto temos a Figura 25 a qual retrata o tempo que leva para percorrer as distâncias parciais conforme a BPM varia. Observe que a cada padrão $P_{i}=\left[p_{1}^{i}, p_{2}^{i}, p_{3}^{i}, \ldots, p_{n_{i}}^{i}\right]$ da sequência $S$, está associado um conjunto de índices $B_{i}=\left\{b_{1}^{i}, b_{2}^{i}, b_{3}^{i}, \ldots, b_{m_{i}}^{i}\right\}$

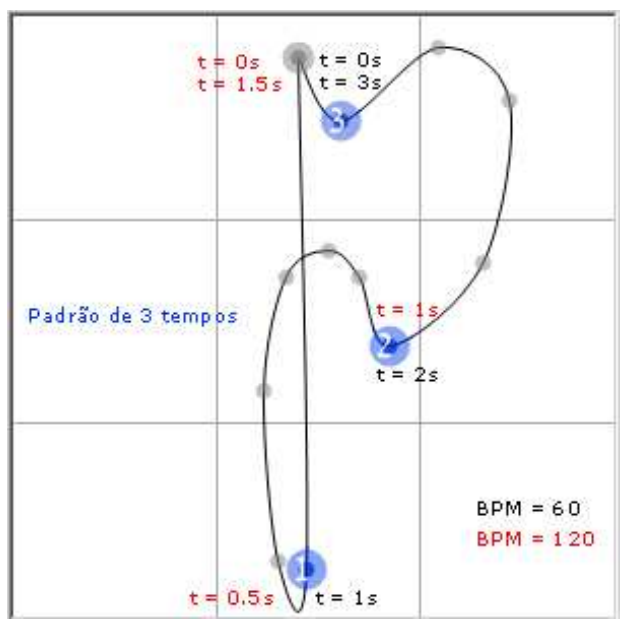

Figura 25 - Padrão de 3 tempos em diferentes BPM.

Sabemos que a taxa de atualização de tela do Podium do Regente é de $\frac{1}{60} s$. Portanto, deverá existir um conjunto o qual cada elemento represente um incremento desta taxa. Portanto, seja $T=\left\{\frac{1}{60}, \frac{2}{60}, \frac{3}{60}, \ldots, \frac{60}{c}\right\} \subseteq \mathbb{R}$ o conjunto de taxas de atualização, considere a função $w_{i}:\left\{1,2,3, \ldots, m_{i}\right\} \times T \rightarrow \mathbb{R}^{2}$, definida da seguinte forma:

$$
w_{i}(k, t)=p_{b_{\left(k-2 \bmod \left(m_{i}\right)\right)+1}^{i}}^{i}\left\lfloor\left[b_{\left(k-2 \bmod \left(m_{i}\right)\right)+1}^{i}-b_{k}^{i}\right) \times \operatorname{sen}\left(\frac{\Pi}{2} \times \frac{c t}{60}\right)\right\rfloor
$$

A função acima equivale a dizer que os pontos no intervalo de pontos definido em função de $k$ são percorridos ao longo do tempo $t$ utilizando a função seno a qual possui valor máximo quando $t=\frac{60}{c}$. Aqui a subtração dos índices é utilizada para obter a distância parcial (quantidade de pontos) entre as duas marcações de tempo, o 
qual é multiplicado pelo resultado do seno. Isto, após arredondamento, retornará um índice de $B^{i}$ que é somado ao índice do tempo de início. Desta forma, para $i \in\{1, o\}$, com $1 \leq o \leq 2$ e $k \in\left\{1,2,3, \ldots, m_{i}\right\}$ e $t \in T$, é gerada uma sequência em $\mathbb{R}^{2}$ em função do seno, simulando um movimento mais próximo do real.
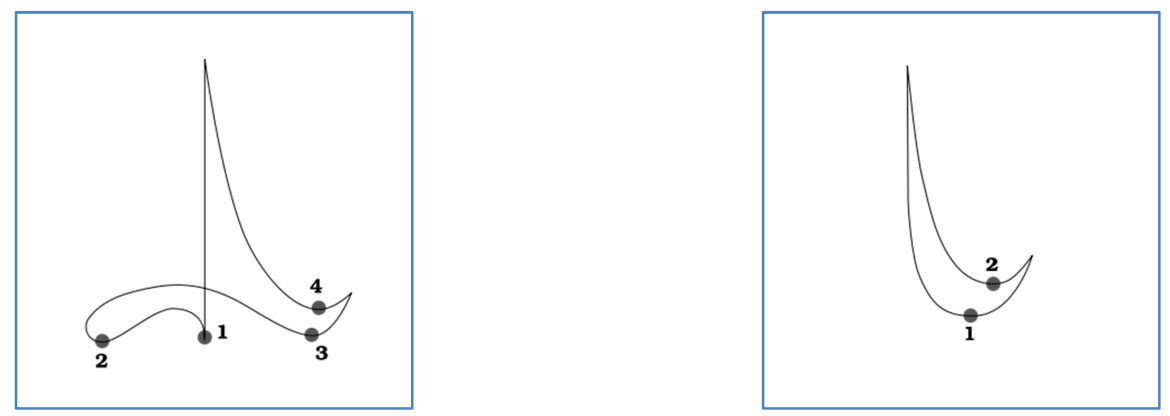

Figura 26 - Exemplo de padrão de regência de 4 Figura 27 - Exemplo de padrão de regência de 2 tempos P1. tempos P2.

Por exemplo, $P_{1}$ o padrão de regência de 4 tempos ilustrado pela Figura 26 e $P_{2}$ o padrão de regência de 2 tempos ilustrado pela Figura 27. Se assumirmos $B_{1}=$ $\{65,120,180,249\}, B_{2}=\{29,120\}, S=\left[P_{1}, P_{2}\right]$, e $c=60$ (BPM), teremos a seguinte tabela:

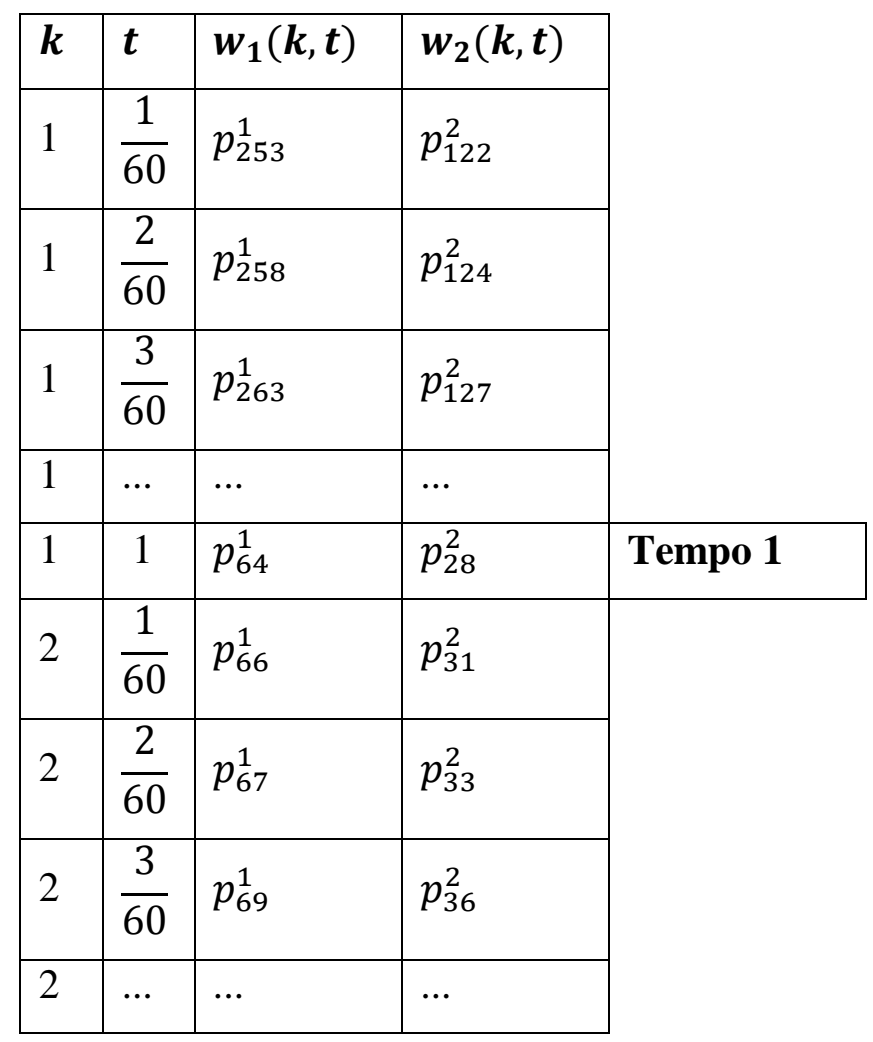




\begin{tabular}{|c|c|c|c|c|}
\hline 2 & 1 & $p_{119}^{1}$ & $p_{119}^{1}$ & Tempo 2 \\
\hline 3 & $\frac{1}{60}$ & $p_{121}^{1}$ & & \\
\hline 3 & $\frac{2}{60}$ & $p_{123}^{1}$ & & \\
\hline 3 & $\frac{3}{60}$ & $p_{124}^{1}$ & & \\
\hline 3 & $\ldots$ & $\ldots$ & & \\
\hline 3 & 1 & $p_{179}^{1}$ & & Tempo 3 \\
\hline 4 & $\frac{1}{60}$ & $p_{181}^{1}$ & & \\
\hline 4 & $\frac{2}{60}$ & $p_{193}^{1}$ & & \\
\hline 4 & $\frac{3}{60}$ & $p_{185}^{1}$ & & \\
\hline 4 & $\cdots$ & $\cdots$ & & \\
\hline 4 & 1 & $p_{248}^{1}$ & & Tempo 4 \\
\hline
\end{tabular}

Tabela 1 - Amostra de valores de $w_{i}(k, t)$ para $P_{1}$ e $P_{2}$.

Sabemos que $w_{i}(k, t)$ retorna valores em $\mathbb{R}^{2}$, entretanto, queremos analisar o movimento do usuário, fornecido pelo o Kinect, em $\mathbb{R}^{3}$. Por isso, precisamos definir uma função que leve os valores de $w_{i}(k, t)$ para $\mathbb{R}^{3}$. Desta forma, para obtermos o valor do novo eixo utilizamos o plano de profundidade associado ao padrão de regência $P_{i}$. Isto é, seja:

- $l_{i} \in\{15,25,35\}=$

$\left\{\begin{array}{l}15, \text { se o padrão } P_{i} \text { está no plano de profundidade próximo } \\ 25 \text {, se o padrão } P_{i} \text { está no plano de profundidade médio } \\ 35 \text {, se o padrão } P_{i} \text { está no plano de profundidade distante }\end{array}\right.$

- $w_{i}(k, t)=\left(x_{k, t}^{i}, y_{k, t}^{i}\right) \in P_{i}$

Definimos a função $\varphi: \mathbb{R}^{2} \rightarrow \mathbb{R}^{3}$ tal que $\varphi\left(w_{i}(k, t)\right)=\left(x_{k, t}^{i}, y_{k, t}^{i}, l_{i}\right)$. Como sabemos que existe uma sequência de sequências definimos $A=\left[S_{1}, S_{2}, S_{3}, \ldots, S_{e}\right]$, onde $S_{\hat{\imath}} \in A$, e $\mathrm{F}=\left\langle d \mid d=\left[\varphi\left(w_{i}(k, t)\right)_{\hat{\imath}^{\prime}} \varphi\left(w_{o}(k, t)\right)_{\hat{1}}\right]\right\rangle$ como a sequência de frames que formam o arquivo de prática sintética final. 


\subsubsection{Algoritmo de Cálculo de Nota de Execução de Prática}

Para que o estudante possa ser avaliado quantitativamente, ao término do treinamento é calculada uma nota resultante da média da média da soma das distâncias entre as posições tridimensionais das juntas corporais entre o movimento realizado com o esperado.

Entretanto para que possamos definir o conceito de pior e melhor nota foi necessário atribuir um valor para caracterizar a pior distância possível a qual chamaremos de $d \in \mathbb{R}$.

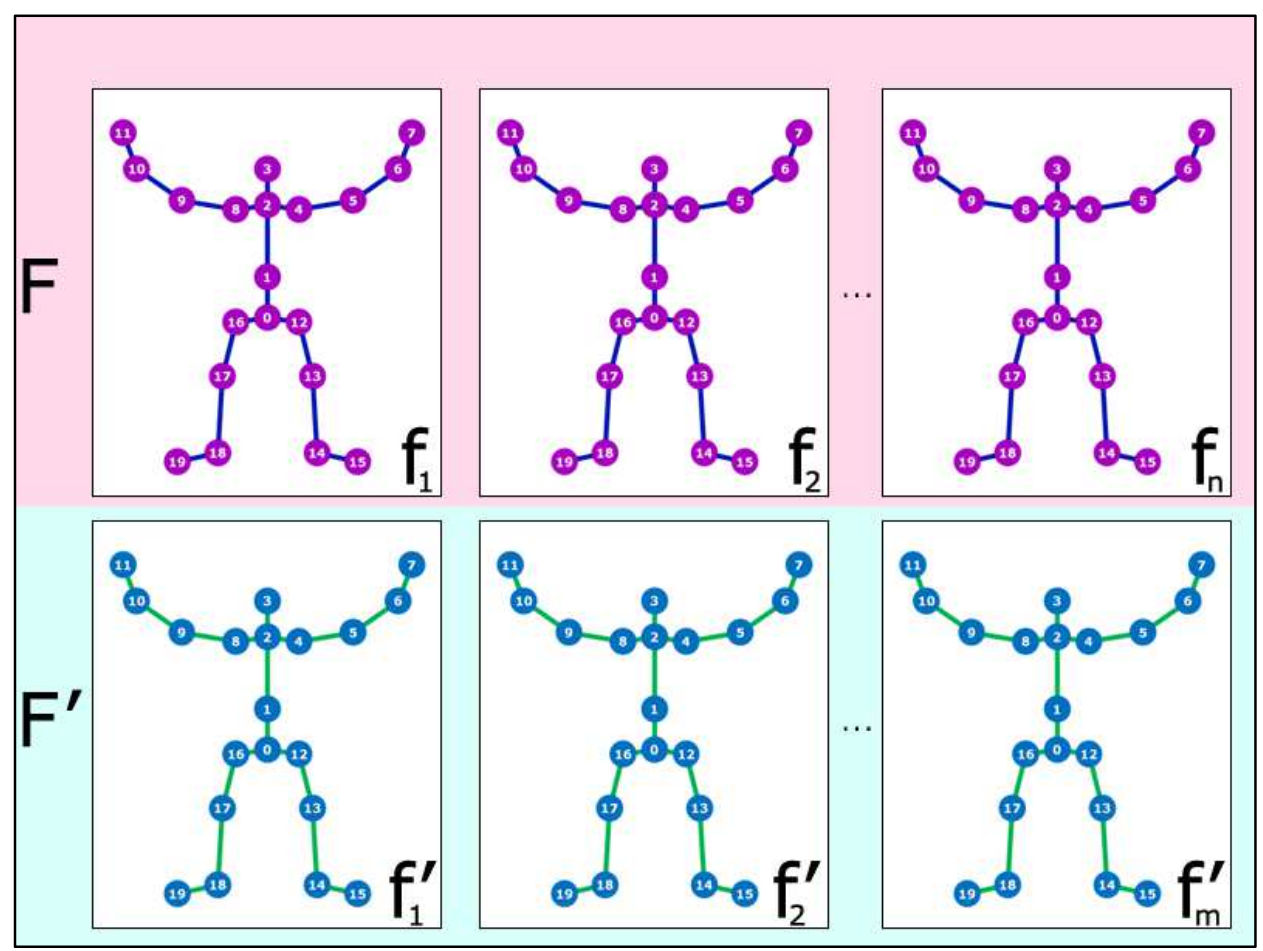

Figura 28 - Comparação de frames de dois conjuntos $F$ e F'.

Tomando como exemplo a Figura 28 e considerando que o Kinect captura 20 juntas corporais, para cada frame $f_{i}=\left[\left(x_{1}, y_{1}, z_{1}\right),\left(x_{2}, y_{2}, z_{2}\right),\left(x_{3}, y_{3}, z_{3}\right), \ldots,\left(x_{20}, y_{20}, z_{20}\right)\right] \in F$ $f_{i}^{\prime}=\left[\left(x^{\prime}{ }_{1}, y^{\prime}{ }_{1}, z^{\prime}{ }_{1}\right),\left(x^{\prime}{ }_{2}, y_{2}^{\prime}, z^{\prime}{ }_{2}\right),\left(x_{3}^{\prime}, y_{3}^{\prime}, z^{\prime}{ }_{3}\right), \ldots,\left(x_{20}^{\prime}, y_{20}^{\prime}, z^{\prime}{ }_{20}\right)\right] \in F^{\prime}$ calculamos $g_{i}$, o qual representa a média da soma das distâncias das juntas corporais entre $f_{i}$ e $f^{\prime}{ }_{i}$ da seguinte forma:

$$
g_{i}=\frac{1}{20} \sum_{j=1}^{20} \min \left\{d, \sqrt{\left(x_{j}-x_{j}^{\prime}\right)^{2}+\left(y_{j}-y^{\prime}{ }_{j}\right)^{2}+\left(z_{j}-z^{\prime}{ }_{j}\right)^{2}}\right\}
$$


O resultado de $g_{i}$ é a média da soma das distâncias euclidianas dos pontos que compõe os frames $f_{i}$ e $f^{\prime}{ }_{i}$. Durante a somatória, verificamos se a distância calculada é maior do que $d$, e se isto for verdade, armazenaremos a pior distância.

Seja $k=\min \left\{|F|,\left|F^{\prime}\right|\right\} \in \mathbb{N}^{*}$, se acumularmos valores de $g_{i}$ para cada par de frames enquanto $i \leq k$ for uma condição válida, podemos somar tais valores $\mathrm{e}$ calcular a média final com base nos $k$ frames analisados. Portanto, podemos calcular a nota final $n \in \mathbb{R}$ da seguinte forma:

$$
n=100-\left(\frac{\frac{1}{k} \sum_{i=1}^{k} g_{i}}{d} \times 100\right)
$$

Por exemplo, se todas as distâncias calculadas forem maiores ou iguais a $d$, então $g_{i}=d, \operatorname{logo}$ :

$$
n=100-\left(\frac{\frac{1}{k} \sum_{i=1}^{k} d}{d} \times 100\right)=100-\left(\frac{\frac{d k}{k}}{d} \times 100\right)=100-\left(\frac{d}{d} \times 100\right)=100-100=0
$$

De forma contrária, se todas as distâncias calculadas forem iguais a zero, isto é, o movimento realizado pelo usuário foi perfeito, então $g_{i}=0$, logo:

$$
n=100-\left(\frac{\frac{1}{k} \sum_{i=1}^{k} 0}{d} \times 100\right)=100-\left(\frac{\frac{d 0}{k}}{d} \times 100\right)=100-\left(\frac{0}{d} \times 100\right)=100-0=100
$$

É importante mencionar que a marcação de tempo na regência coral é um fator importante, ou seja, se um regente inicia o movimento 5 segundos após o esperado, este movimento estará errado. Analogamente, se alguém vai a um videokê e canta a música que é exibida no monitor com um atraso de 5 segundos em relação à legenda, a música estará errada também, ou melhor, a música foi cantada corretamente, mas fora do tempo esperado. Esta é a razão pela qual o algoritmo não busca uma correspondência entre os frames para que a comparação seja realizada.

\subsubsection{Algoritmo de Detecção Automática dos Tempos nos Padrões de Regência}

Uma das funcionalidades da Biblioteca de Padrões vistas na Seção 4.3 é a detecção automática dos tempos no padrão de regência. Esta funcionalidade pode ser compreendida como um problema de localização dos mínimos locais de uma função $f(x)$. 
Dizemos que um uma função $f(x)$ possui um mínimo em $x=a$ se $f(a)$ for menor do que qualquer valor anterior ou posterior a $a$ denotado por $b$ tal que $f(b)>f(a)$.

Entretanto, como na aplicação não temos uma função que caracterize a curva a qual representa o padrão de regência, mas somente pontos representando coordenadas bidimensionais, podemos realizar a observação da alteração dos valores no eixo y, da seguinte maneira:

Seja $Y=\left(y_{1}, y_{2}, y_{3}, \ldots, y_{n}\right) \in \mathbb{Z}$ a sequência dos valores do eixo y para os pontos pertencentes ao padrão de regência configurado e $y_{i} \in Y$ tal que $y_{i}$ é considerado mínimo, se $y_{i} \leq y_{\max \{0, i-1\}}$ e $y_{i} \leq y_{\min \{n, i+1\}}$.

\subsection{Usabilidade}

Um dos fatores de sucesso de um software é sua usabilidade. Segundo ABNT (2002), usabilidade é proporcionar que usuários alcancem seus objetivos e satisfaçam suas necessidades em um contexto particular de uso.

Desta forma, os conceitos básicos da NBR 9241-11 - padrão responsável por definir o conceito de usabilidade em software, foram aplicados para tornar a experiência do usuário agradável e mensurável, permitindo determinar se os estudantes e professores de regência coral consideram o uso do produto aceitável.

O contexto de uso de um software consiste em: usuários, tarefas, equipamentos (hardware, software e materiais), e do ambiente físico e social, pois todos esses podem influenciar a usabilidade de um produto dentro de um si stema de trabalho. No tocante do ensino da regência podemos descrever estes itens da seguinte maneira:

- Hardware - deverá ser de simples manipulação para o usuário final, que não deverá se preocupar com complexidades, especificidades ou problemas técnicos para que consiga usufruir do software proposto. Isso é necessário porque pressupõe-se que o público-alvo não possui conhecimento técnico profundo para lidar com tais desafios e problemas técnicos. O uso do Kinect contribui neste sentido já que para fazê-lo funcionar basta conectar o sensor à tomada e ao computador via entrada USB; 
- Ambiente físico - os possíveis ambientes para o uso do software são: (i) salas de aula; (ii) anfiteatros; (iii) teatros; (iv) ginásios; (v) ambientes externos; (vi) outros. A principal diferença entre estes é a variação de luminosidade. Entretanto, como o Kinect foi escolhido como sensor, e como este utiliza feixes de raios infravermelhos para obter o mapa de profundidade do usuário em cena (posição tridimensional das juntas corporais), a luminosidade do ambiente é indiferente para o resultado final da captura;

- Ambiente social - composto majoritariamente por estudantes e professores de regência coral. Portanto, o linguajar utilizado pelo software deverá seguir os termos técnicos utilizados no ensino da regência coral, facilitando a ambientação e reduzindo o tempo de aprendizado do software;

- Software - a ser descrito adiante nesta Seção. Entretanto, segundo MORIMOTO (2005), os seguintes princípios de usabilidade deverão ser seguidos:

- Fácil de aprender, requerendo pouco treinamento formal;

- Facil de memorizar;

- Maximizador da produtividade, permitindo a realizando de tarefas de forma eficiente e rápida;

- Minimizador da taxa de erros, informando o usuário corretamente e possibilitando fácil correção;

- Maximizador da satisfação do usuário, dando-lhe confiança e segurança.

Para que isto ocorra, é necessário compreender o contexto que permeia o software, seu propósito, qual ambiente este estará inserido, a linguagem e a linha de pensamento utilizadas pelos indivíduos participantes e inseridos no contexto. Tudo isso pode ser resumido em uma palavra: ergonomia. E a tradução desta para o universo do software se dá através de ferramentas que a atendam, representadas por diálogos de interface, fontes, campos, botões, disposição da informação, teclas de atalho, etc.

O processo de tradução descrito acima geralmente ocorre através de técnicas de avaliação baseadas em casos de usos, protótipos ou outros sistemas tomados como 
base e que são utilizados para validar o design do software em desenvolvimento. A Figura 29 ilustra todo processo citado:

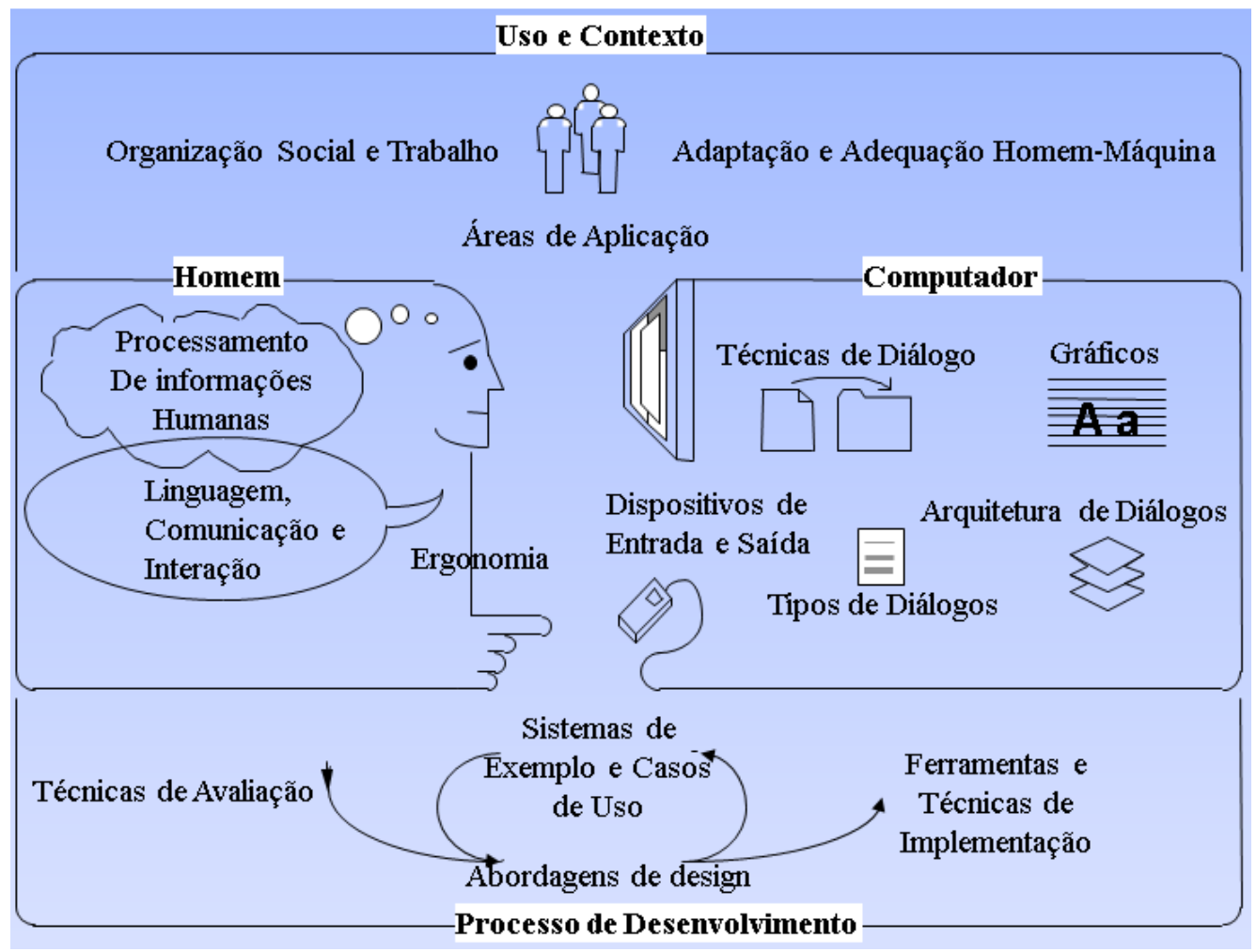

Figura 29 - Visão Geral da Interação Homem-Computador.

\section{Adaptado de GREENBERG (2004).}

No software desenvolvido o uso e o contexto da aplicação foram compreendidos através do contato direto com os alunos e o professor de regência coral durante um semestre de aula, em encontros que ocorriam duas vezes por semana. Com isso, pôde-se compreender também a linguagem e a maneira com que as informações eram processadas pelos alunos à medida que o professor expunha novos tópicos de regência coral - isto pode ser entendido como o Processamento De Informações Humanas e a compreensão da Linguagem, Comunicação e Interação, ambos representados na Figura 29.

O refinamento do software desenvolvido, principalmente no tocante da interface de usuário, ocorreu através da validação de protótipos. A principal vantagem desta abordagem (prototipação) é que o software é desenvolvido sem grandes desvios dos requisitos já que a cada iteração melhorias são realizadas de modo a manter o software fiel às funcionalidades inicialmente listadas. 
O principal desafio foi disponibilizar a interface do software da melhor maneira possível para o usuário final, focando nos princípios citados anteriormente. A razão disto foi devido ao fato do usuário final não saber claramente o que é possível de ser realizado através da tecnologia, razão pela qual a participação direta durante a disciplina e o uso da prototipação terem sido fundamentais na criação do software final.

\subsection{Experiência do Usuário}

De acordo com o modelo de HASSENZAHL (2004), os usuários constroem os atributos de um produto através da combinação de funcionalidades (e.g. apresentação, conteúdo, funcionalidade e interação) com suas expectativas e percepções pessoais. Já o caráter de um produto é um grupo destes atributos que pode ser compreendido como uma estrutura cognitiva que integra tais atributos e suas covariações.

Ainda segundo tal modelo, dois grupos distintos de atributos existem: os pragmáticos e os hedônicos. Os pragmáticos estão conectados com a necessidade do usuário em conseguir atingir seus objetivos ao utilizar o produto, e acima de tudo, atingir os objetivos requer utilidade e usabilidade. Desta forma, um produto que permita ao usuário alcançar seus objetivos de maneira eficaz e eficiente é percebido como pragmático.

Em contraste, os hedônicos estão relacionados à percepção interior do usuário, ou seja, com a (1) estimulação e (2) identificação do usuário mediante ao uso da ferramenta que respectivamente, de acordo com LEVENTHAL et al. (1996) e LOGAN et al. (1994), estão ligados a (i) novidades e desafios; e (ii) o desejo do ser humano se expressar através de objetos - sendo ambos necessidades humanas. Isso torna o estudo da experiência do usuário subjetiva (LAW et al. apud ROTO et al; 2009). O software presente tratou os atributos pragmáticos, já que o estudo dos atributos hedônicos requer profundo estudo da cognição humana.

\subsection{Arquitetura do Software}

A arquitetura retrata todos os componentes utilizados pelo sistema, expressando suas funções e as interações entre os seus componentes. De acordo com SEI (2013), a arquitetura de um software descreve um sistema computacional e auxilia no 
entendimento de como este se comportará. Ela serve como documento e guia para a equipe do projeto, já que define tarefas que deverão ser cumpridas durante o desenho e desenvolvimento da solução. A arquitetura é a primeira responsável pelas qualidades do sistema como: (i) desempenho, (ii) flexibilidade e (iii) segurança - estas não podem ser obtidas sem uma visão arquitetural unificada. Por último, a arquitetura é um artefato utilizado durante as análises iniciais e é utilizada para certificar que a abordagem de desenho da solução leva a um sistema aceitável. Através da construção de uma arquitetura efetiva, riscos podem ser identificados e mitigados nos estágios iniciais do desenvolvimento.

As premissas que foram utilizadas para realizar o desenho da arquitetura do sistema foram:

- Promoção da troca de arquivos de configuração entre usuários. Alguns exemplos disto seriam:

○ Professor envia por e-mail um arquivo de configuração contendo uma nova prática para que um grupo de estudantes a realize;

- Estudante envia o resultado da realização da prática (treinamento) para o professor, que poderá visualizá-la e analisála, utilizando as funcionalidades citadas em 4.3;

- Novo padrão de regência é criado e compartilhado entre os alunos para que novas práticas possam ser criadas utilizando-o.

- Armazenar dados em arquivos estruturados, legíveis e que possibilitem a facil leitura tanto por usuários, quanto pelo software. Para atender tal necessidade, o padrão XML foi adotado. Exemplos de configurações que utilizam o padrão:

- Padrões de regência;

<?xml version="1.0"?>
<pattern name="Kurt Thomas - 4 Tempos" comment="Kurt Thomas - 4 Tempos"
tempos="4" maxAvailableHeight="300" maxAvailableWidth="300">
<point type="UNKNOWN" status="A" tempo="-1" x="140" y="20" z="0" />
<point type="UNKNOWN" status="A" tempo="-1" x="142" y="263" z="0" />
<point type="UNKNOWN" status="A" tempo="0" x="155" y="276" z="0" />
<point type="UNKNOWN" status="A" tempo="-1" x="155" y="140" z="0" />
<point type="UNKNOWN" status="A" tempo="-1" $\mathrm{x}=" 106 " \mathrm{y}=" 128 " \mathrm{z}=$ "0" />




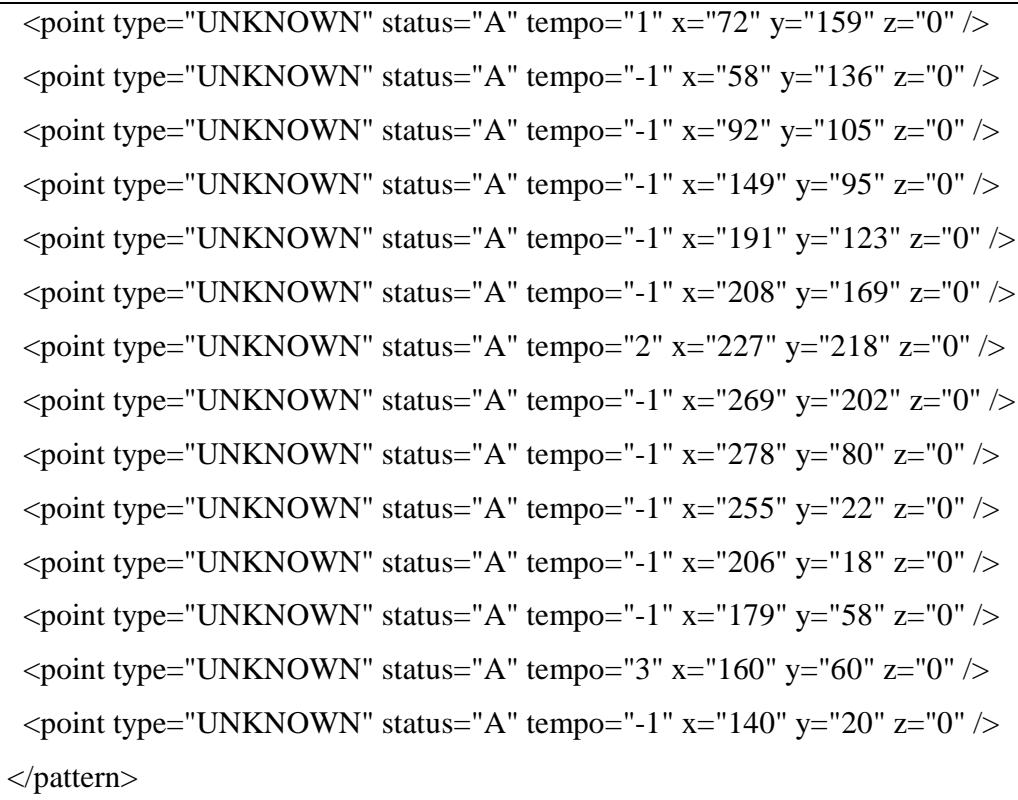

Tabela 2 - XML referente ao padrão exibido na Figura 17.

Na tabela Tabela 2 acima, o elemento pattern identifica unicamente um padrão de regência configurado anteriormente na Biblioteca de Padrões (ver Figura 17). Este elemento possui quatro atributos: (a) name - o qual identifica unicamente o nome do padrão; (b) comment - comentário o qual explica o padrão, sendo opcional; (c) tempos - identifica quantos tempos existem no padrão criado; (d) maxAvailableHeight - valor o qual identifica o tamanho vertical da janela no qual o padrão foi criado - este valor é utilizado para conseguir escalar o padrão em outras telas de maneira apropriada; e (e) maxAvailableWidth - valor o qual identifica o tamanho horizontal da janela no qual o padrão foi criado - este valor é utilizado para conseguir escalar o padrão em outras telas de maneira apropriada.

Os demais elementos, identificados por point representam um ponto de controle o qual faz parte do padrão de regência. Este ponto de controle é identificado pelos seguintes atributos: (i) type - identifica o tipo do ponto, quando o ponto não pertence a um movimento gravado, onde sabe-se a qual parte corporal ele se refere, ele é classificado como UNKNOWN, como no exemplo acima; (ii) status - identifica se 
o ponto está ativo (A) ou inativo (I). Pontos inativos são utilizados para indicar que o ponto não deverá ser utilizado para validação. É utilizado no caso de práticas sintéticas, onde todas as juntas corporais são geradas, mas efetivamente somente as juntas das mãos são válidas; (iii) tempo - identifica se o ponto de controle é uma marcação de tempo (valor maior ou igual a zero) ou não (-1); (iv) $x$ - valor do ponto no eixo x; (v) $y$-valor do ponto no eixo y; (vi) $z$ - valor do ponto no eixo y, como o Editor de Padrões trabalha somente em dois eixos (x, y), o valor de z sempre será zero. Entretanto, este eixo foi deixado para que no futuro, caso o editor funcione tridimensionalmente, haja suporte adequado.

o Práticas sintéticas - para estas dois arquivos são gerados:

- Arquivo com representação da configuração realizada no Editor de Práticas de Regência;

- Arquivo contendo sequência interpolada de pontos seguindo as sequências configuradas no Editor de Práticas de Regência e que será utilizado efetivamente para comparação com os movimentos realizados pelo estudante ou durante o modo de exibição (replay);

- Práticas gravadas - aqui também depois arquivos são gerados:

- Arquivo com representação da prática gravada - contém informações básicas sobre quem gravou tal prática (Tabela 3). Neste são identificados o título da prática (elemento title); a data de criação da mesma (elemento creationDate); e o arquivo o qual contém os dados das coordenadas capturadas (elemento datafile):

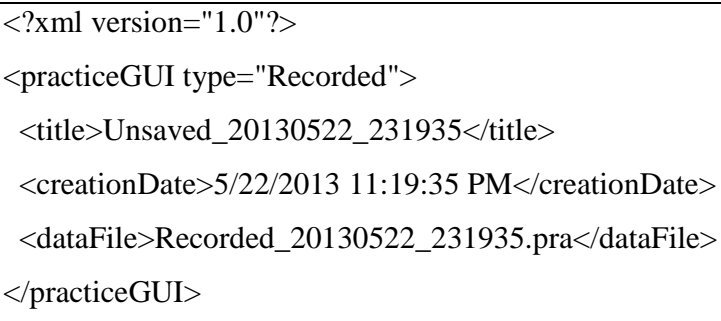


Tabela 3 - XML de representação de prática gravada

- Arquivo com dados capturados pelo sensor - como não há configuração via Editor de Práticas de Regência, o arquivo gerado equivale ao arquivo de interpolação citado para as práticas sintéticas logo acima, com a única diferença de que, diferentemente de uma prática sintética onde diversas sequências existem, neste tipo de prática há somente uma única sequência com todas as coordenadas dentro deste nó XML.

Desta forma, como toda informação armazenada segue o padrão XML, caso deseje, é possível criar novas interfaces gráficas para o usuário final, de modo que estas gerem arquivos no mesmo formato XML estabelecido, garantindo assim a compatibilidade entre tais interfaces e as já existentes.

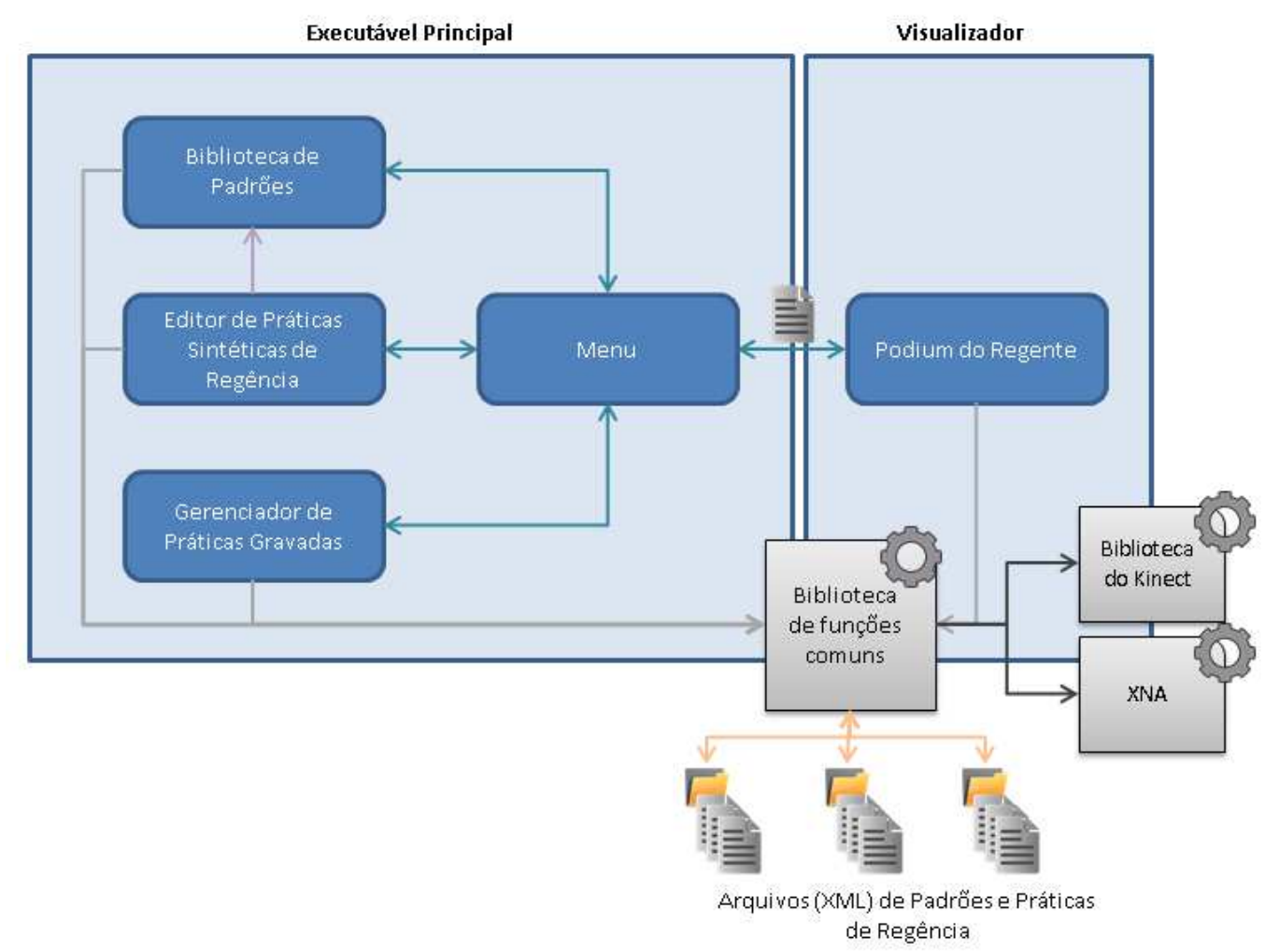

Figura 30 - Arquitetura do software.

A Figura 30 ilustra os componentes abordados nesta seção, assim como as bibliotecas envolvidas. Pode-se ver que há um menu principal o qual guia o usuário entre os diferentes módulos da aplicação. Quando o usuário deseja visualizar ou treinar 
uma das práticas criadas, ele utiliza o visualizador (Podium do Regente) o qual recebe os arquivos XML de práticas como entrada. Todos os módulos fazem uso de uma biblioteca com funções e classes (objetos) de uso comum entre os módulos, além das bibliotecas nativas do Kinect e do XNA para realizar, respectivamente, a captura das coordenadas corporais do corpo do usuário e a exibição de tais informações na tela. 


\section{Capítulo 5: Conclusão}

\section{$5.1 \quad$ Resultados Obtidos}

Foram comparadas notas de 5 alunos de graduação em regência coral que realizaram 10 treinamentos consecutivos de uma mesma prática sintética onde todos os planos de profundidade eram explorados.

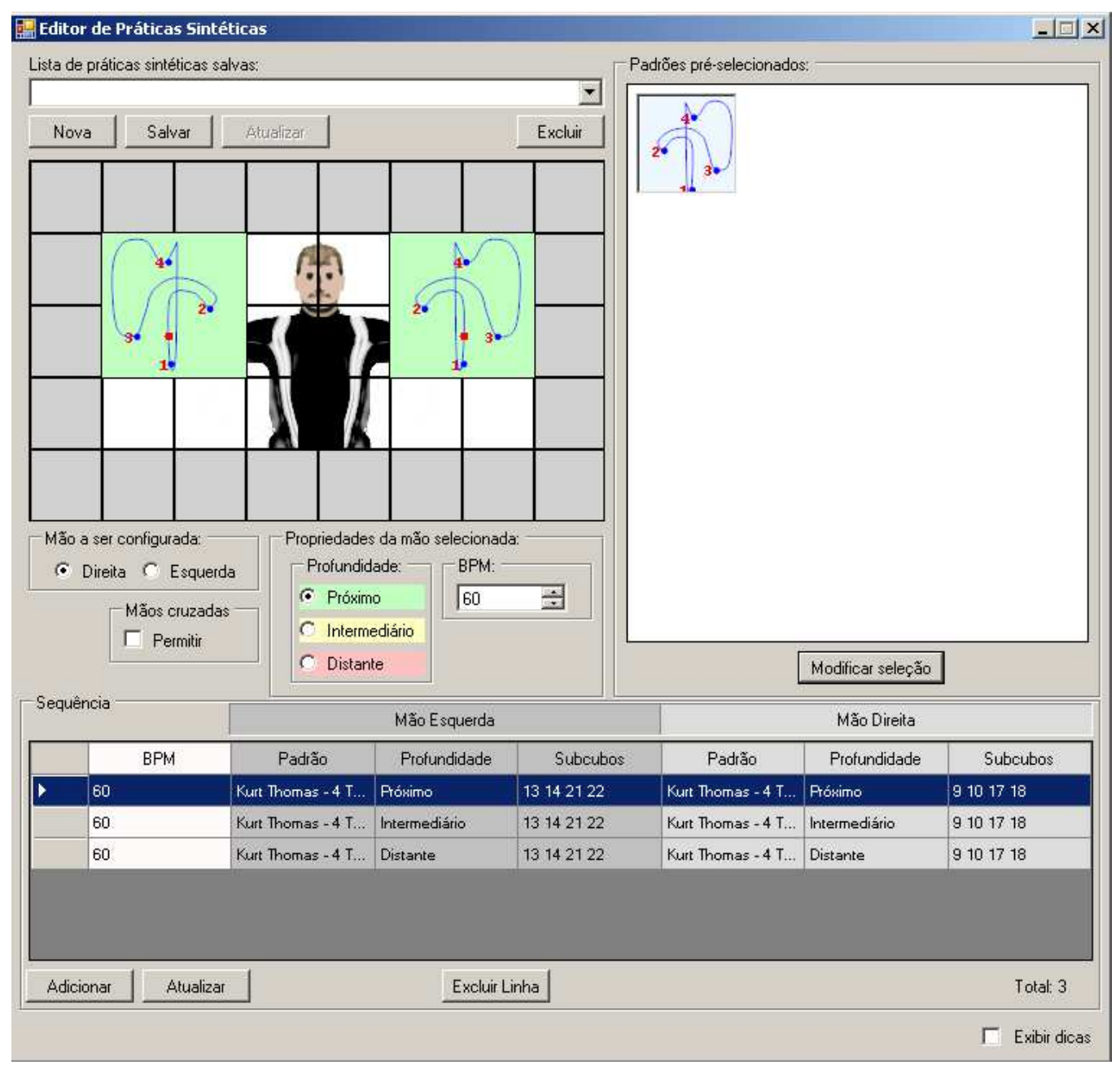

Figura 31 - Prática sintética utilizada para treinamento.

Pôde-se observar que ao término do décimo treinamento, houve uma significativa melhora na execução dos movimentos por parte dos estudantes, como pode ser visto na Tabela 4 a seguir: 


\begin{tabular}{|c|c|c|c|c|c|c|c|c|c|c|c|c|}
\hline \multirow[b]{2}{*}{ Estudante } & \multicolumn{10}{|c|}{ Treinamento } & \multirow{2}{*}{$\begin{array}{c}\text { Cresc. 1-10 } \\
\%\end{array}$} & \multirow{2}{*}{$\begin{array}{c}\text { Cresc. 6-10 } \\
\% \\
\end{array}$} \\
\hline & 1 & 2 & 3 & 4 & 5 & 6 & 7 & 8 & 9 & 10 & & \\
\hline 1 & 64 & 66 & 69 & 70 & 75 & 74 & 76 & 80 & 79 & 78 & 21.9 & 5.41 \\
\hline 2 & 25 & 29 & 26 & 28 & 27 & 29 & 32 & 40 & 42 & 43 & 72 & 48.28 \\
\hline 3 & 58 & 63 & 67 & 69 & 72 & 74 & 71 & 75 & 73 & 74 & 27.6 & 0 \\
\hline 4 & 49 & 47 & 45 & 52 & 50 & 49 & 53 & 55 & 54 & 56 & 14.3 & 14.29 \\
\hline 5 & 36 & 42 & 45 & 47 & 49 & 58 & 52 & 53 & 59 & 55 & 52.8 & -5.17 \\
\hline Média & 46.4 & 49.4 & 50.4 & 53.2 & 54.6 & 56.8 & 56.8 & 60.6 & 61.4 & 61.2 & 31.9 & 7.75 \\
\hline
\end{tabular}

Tabela 4 - Resultado de 10 treinamentos consecutivos para 5 usuários.

Através da Tabela 4, observamos um avanço de $31.9 \%$ entre a média das primeiras e das últimas notas dos estudantes. Entretanto, esse percentual deve ser compreendido com cautela, já que nos treinamentos iniciais o usuário, embora não em todos os casos, ainda não estava familiarizado com o software, justificando assim as notas baixas iniciais. Portanto, de modo a obter uma taxa de crescimento mais próxima da real, outro percentual foi obtido considerando os treinamentos do sexto em diante, o qual restou em uma média de $7.75 \%$, o que parece refletir melhor a realidade, já que é mais difícil aprimorar a técnica a partir quando se domina a ferramenta, neste caso, caso o software.

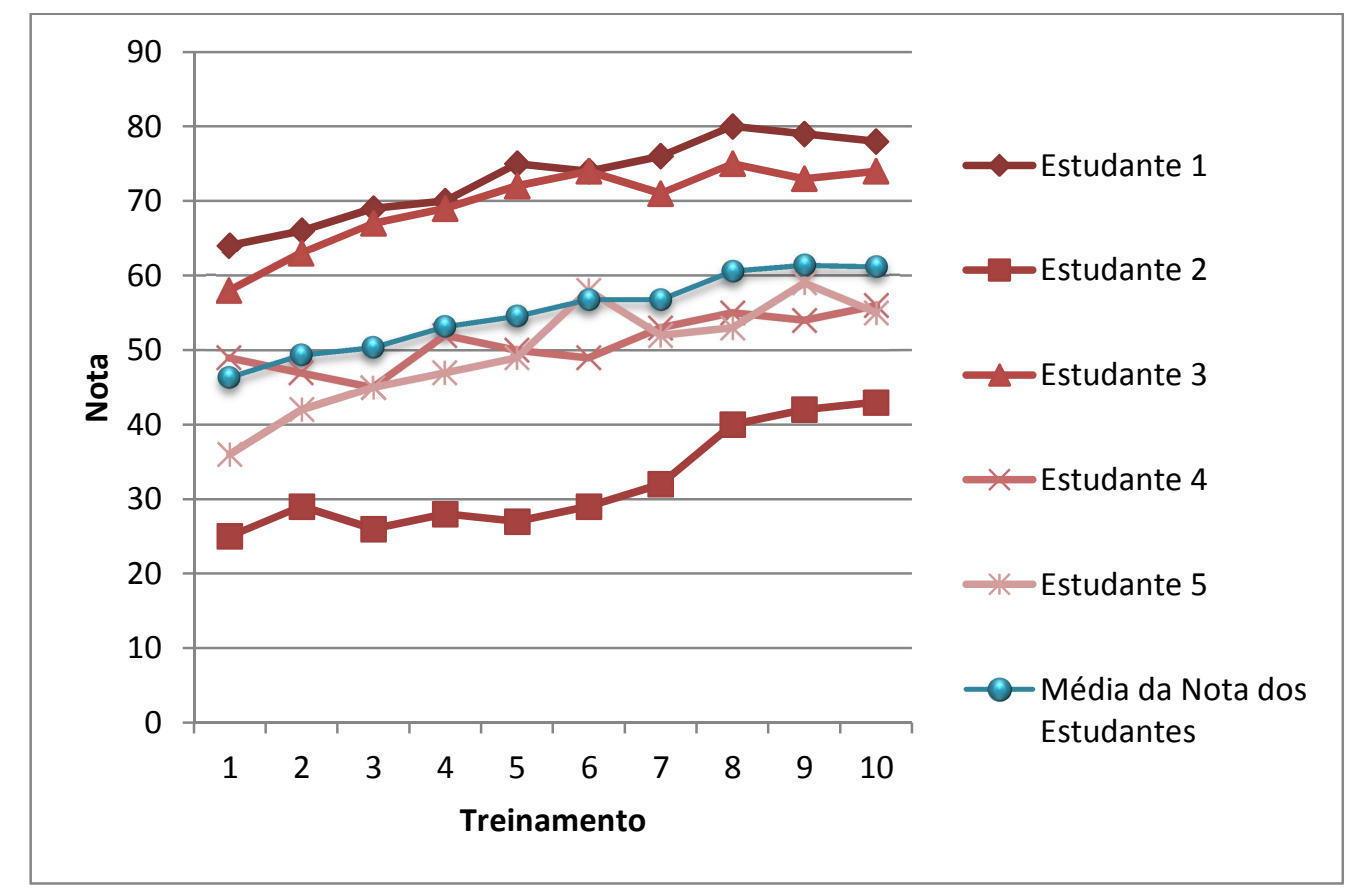

Figura 32 - Análise do resultado dos treinamentos.

De qualquer modo, pode-se concluir que o software ajudou no aprimoramento do movimento realizado pelo estudante durantes a execução da prática. Um ponto 
importante a ser observado é que pode-se dizer que nenhum estudante conseguiu obter uma nota superior a 80, o que indica que o critério de avaliação utilizado talvez esteja muito rígido e precise de alguns ajustes.

\subsection{Principais Desafios}

O tempo de implementação do software foi de aproximadamente 708 horas, extrapolando o planejado no cronograma exibido durante o exame e documento de qualificação. As principais causas para isto ter ocorrido foram:

- Desafios técnicos maiores do que o esperado:

○ Dificuldade na realização do mapeamento de juntas corporais ao modelo tridimensional exibido;

○ Esforço excessivo para a geração de dados interpolados a partir de configuração da prática sintética;

○ Adaptações arquiteturais para suportar funcionalidades;

○ Estudo dos algoritmos aplicados.

- Ajustes para refletir corretamente conceitos da regência coral;

- Estudo sobre usabilidade e experiência do usuário.

\subsection{Contribuições}

Este trabalho, embora seja focado para o ensino da regência coral, pode ser utilizado como base de expansão para outras áreas como:

- Reabilitação de movimentos, entre outras áreas da fisioterapia;

- Treinamentos esportivos, onde movimentos precisam ser aprimorados;

- Áreas correlatas da regência e música.

Além das áreas supracitadas, qualquer outra que utilize movimentos corporais para um determinado objetivo poderá ser beneficiada, já que o software apresentado pode ser compreendido como uma plataforma de comparação de movimentos corporais. 


\subsection{Próximos Passos}

Observou-se que as interfaces ainda precisam ser melhoradas. O Podium do Regente, por exemplo, poderia fornecer informações sobre os movimentos executados pelo usuário em tempo de execução, indicando por exemplo:

- Quanto que o movimento está sendo realizado corretamente - por exemplo, indicar através de cores (gradiente do vermelho ao verde pior ao melhor);

- O que o estudante pode fazer para corrigir seu movimento;

- Indicar exatamente onde os erros estão sendo cometidos.

Atualmente, o Podium do Regente gera uma nota ao final, que embora indique algo, não diz precisamente o que deve ser melhorado pelo usuário.

É importante citar que até o momento não existe aplicação com este foco específico, portanto a criação de artigos multidisciplinares e a publicação de artigos em revistas de regência coral é uma possibilidade real. 


\section{Capítulo 6: Referências Bibliográficas}

ABNT - ASSOCIAÇÃO BRASILEIRA DE NORMAS TÉCNICAS. NBR 9241-11: Requisitos Ergonômicos para Trabalho de Escritórios com Computadores. Parte 11 - Orientações sobre Usabilidade, 2002. Disponível em http://www.inf.ufsc.br/ cybis/pg2003/iso9241-11F2.pdf. Acessado em 02/06/2011.

AGÊNCIA DETALHES. Kinect Educação, 2011. Disponível em http://www.kinecteducacao.com.br/. Acessado em 16/02/2011.

ANDERSON, Ronald. Conducting Clarity Through the "Box Technique!", s.d. Disponível em http://www.tsmp.org/choir/randerson/anderson_conducting_clarity.html. Acessado em 08/06/2013.

BOURKE, Paul. Interpolation Methods, 1999. Disponível em http://paulbourke.net/miscellaneous/interpolation/. Acessado em 28/07/2013.

BRANCO, Heloiza de Castello. A contribuição do estudo do sistema laban para o gestual do regente, s.d. Disponível em http://www.uel.br/pos/musica/pages/arquivos/LabanSimpemus.pdf. Acessado em 28/05/2013.

BRUEGGE, Bernd; TESCHNER, Christoph; LACHENMAIER, Peter; FENZL, Eva; SCHMIDT, Dominik; BIERBAUM, Simon. Pinocchio: Conducting a Virtual Symphony Orchestra, 2007. Universidade Técnica de Munique. Disponível em http://eprints.lancs.ac.uk/41518/1/2007_-_Bruegge\%2C_B_-_Pinocchio_-

_Conducting_a_Virtual_Symphony_Orchestra.pdf. Acessado em 28/02/2012.

CATMUlL, E; ROM, R. A Class of Local Interpolationg Splines, 1974. Computer Aided Geometric Design, Academic Press, Nova Iorque, 1974.

CHESNOKOV, Pavel. The Choir and How to Direct It, 2010. Musica Russica, 2010. 
CORMEN, Thomas H; LEISERSON, Charles E; RIVEST, Ronald L; STEIN Clifford. Introduction to Algorithms, $2^{\text {a }}$. Edição, 2001. The MIT Press.

DECKER, Harold A; HERFORD, Julius. Choral Conducting Symposium 2a Edição, 1988. Prentice Hall, 1988.

DEMAREE, Robert W; MOSES, Don V. The Complete Conductor, 1995. PrenticeHall, 1995.

DESMET, P. M. A. Designing Emotions, 2002. Dissertação de Doutorado. Universidade Técnica de Delft.

DRISCOLL, Michael T. A Machine Vision System for Capture and Interpretation of an Orchestra Conductor's Gestures, 1999. Disponível em http://www.wpi.edu/Pubs/ETD/Available/etd-051199-142455/unrestricted/driscoll.pdf. Acessado em 31/07/2013.

EHMANN, Wilhelm. Choral Directing, 1968. $1^{\text {a }}$ Edição, Augsburg Fortress Pub, 1968.

FUJINAGA, Ichiro; TOBEY, Forest. Extraction of Conducting Gestures in 3D Space, 1996. Disponível em http://quod.lib.umich.edu/cgi/p/pod/dodidx?c=icmc;idno=bbp2372.1996.092. Acessado em 29/02/2012.

GARNETT, Guy E; BRECHT, Bennett. Conductor Follower, 1992. Universidade da Califórnia. Disponível em http://quod.lib.umich.edu/cgi/p/pod/dodidx?c=icmc;idno=bbp2372.1995.056. Acessado em 28/02/2012.

GARRETSON, Robert L. Conducting Choral Music, 1998. $8^{\text {a }}$ Edição, Prentice Hall, 1998.

GEHRKENS, Karl W. ESSENTIALS IN CONDUCTING, 2007. Disponível em http://www.gutenberg.org/files/22392/22392-h/22392-h.htm\#CHAPTER_I. Acessado em 26/05/2013. 
GMCCB, Apostila Livre de Regência: Estudo dirigido para orquestras, s.d. Disponível em http://www.gmccb.com/files/Apostila-Livre-de-Regencia-paraOrquestras-CCB.pdf. Acessado em 03/03/2012.

GREENBERG, Saul. Map of Human Computer Interaction, 2004. Material didático do curso Lecture Topics in Human Computer Interaction da Universidade de Calgary. Disponível em http://pages.cpsc.ucalgary.ca/ saul/hci_topics/powerpoint_presentations/hci_map.ppt. Acessado em 02/06/2013.

GRÜLL, Ingo. conga: A Conducting Gesture Analysis Framework, 2005. Disponível em http://hci.rwth-aachen.de/materials/publications/gruell2005a.pdf. Acessado em 29/02/2012.

HASSENZAHL, M. The interplay of beauty, goodness, and usability in interactive products, 2004. Human-Computer Interaction 19, 4; 2004.

HODGES, Steve; FITZGIBBON, Andrew. KinectFusion: Real-Time Dense Surface Mapping and Tracking, 2011. Artigo apresentado no ISMAR de Outubro de 2011.

HONG, Dongpyo; WOO, Woontack. A Background Subtraction for a Vision-based User Interface, 2003.

HORPRASERT T; HARWOOD, D. A statistical approach for real-time robust background subtraction and shadow detection, 1999. Technical report, Computer Vision Laboratory, University of Maryland, EUA.

HUANG, Zhi-Kai; CHAU, Kwok-Wing. A New Image Thresholding Method Based on Gaussian Mixture Model, 2008. Applied Mathematics and Computation, Vol. 205, Nº. 2, 2008, páginas 899-907.

ICMC. ICMC, 2012. Disponível em http://www.computermusic.org/page/23/. Acessado em 16/02/2012.

IRURTIA, Luis Unzueta. Markerless Full-Body Human Motion Capture And Combined Motor Action Recognition For Human-Computer Interaction, 2009. 
Disponível

em

http://tcc-fei2010.googlecode.com/svn-

history/r3/trunk/PhD_Luis_Unzueta.pdf. Acessado em 16/02/2012.

JÄHNE, Bernd, HAUßECKER, Horst. Computer Vision and Applications: A Guide for Students and Practitioners, 2000. Academic Press, 2000.

JOYSTIQ. Kinect: The company behind the tech explains how it works, 2010. Disponível em http://www.joystiq.com/2010/06/19/kinect-how-it-works-from-thecompany-behind-the-tech/. Acessado em 27/11/2011.

JORDANIA, Joseph. Who Asked the First Question? The Origins of Human Choral Singing, Intelligence, Language and Speech, 2006. Disponível em http://www.polyphony.ge/uploads/whoaskthefirst.pdf. Acessado em 12/04/2011.

JABRI, Sumer; DURIC, Zoran; WECHSLER; Harry; ROSENFELD; Azriel. Detection and Location of People in Video Images Using Adaptive Fusion of Color and Edge Information, 2000.

JOY, Kenneth I. Catmull-Rom Splines, 2002. Disponível em http://graphics.cs.ucdavis.edu/ joy/ecs278/notes/Catmull-Rom-Spline.pdf. Acessado em 17/07/2013.

JUNG, C. F. Metodologia para pesquisa \& desenvolvimento: aplicada a novas tecnologias, produtos e processos, 2004. Rio de Janeiro/RJ: Axcel Books do Brasil Editora, 2004.

KARAMAN, Mustafa; GOLDMANN, Lutz; YU, Da; SIKORA, Thomas. Comparison of Static Background Segmentation Methods, 2005. Disponível em http://elvera.nue.tu-berlin.de/files/0744Karaman2005.pdf. Acessado em 09/01/2011.

KLETTE, Reinhard. Material didático do curso: Advanced Multimedia Imaging: COMPSCI 775 Semester 2, Tamaki Campus, 2007. University of Auckland, New Zealand.

LAW, E; ROTO, V; HASSENZAHL, M; VERMEEREN, A; KORT, J. Understanding, Scoping and Defining User eXperience: A Survey Approach. In 
Proc, 2009. ACM SIGCHI conference on Human Factors in Computing Systems, CHI'09.

LEE, Eric; WOLF, Marius; BORCHERS, Jan. Improving Orchestral Conducting Systems in Public Spaces: Examining the Temporal Characteristics and Conceptual Models of Conducting Gestures, 2005. Universidade de Aachen. Disponível em http://hci.rwth-aachen.de/materials/publications/lee2005a.pdf. Acessado em 28/02/2012.

LEVENTHAL, L; TEASLEY, B; BLUMENTHAL, B; INSTONE, K; STONE, D; DONSKOY, M. V. Assessing user interfaces for diverse user groups: Evaluation strategies and defining characteristics, 1996. Behaviour \& Information Technology.

LOGAN, R. J; AUGAITIS, S; RENK, T. Design of simplified television remote controls: A case for behavioral and emotional usability, 1994. In Proceedings of the $38^{\text {th }}$ Human Factors and Ergonomics Society Annual Meeting (páginas 365-369). Santa Mônica, CA: HFES.

MÄKELÄ, A; FULTON, S, J. Supporting Users' Creativity: Design to Induce Pleasurable Experiences, 2001. Proceedings of the International Conference on Affective Human Factors Design, páginas. 387-394.

MATSUMURA, Keila Keiko; SONNINO, Roberto. Fusion4D - Interface Natural e Imersiva Para Manipulação de Objetos 3D, 2011. Disponível em http://www.interlab.pcs.poli.usp.br/fusion4d/docs/Monografia\%20-\%20Fusion4D.pdf. Acessado em 16/02/2012.

MAURER, Uwe; ROWE, Anthony; SMAILAGIC, Asim; SIEWIOREK Daniel P. eWatch: A Wearable Sensor and Notification Platform, 2006. Universidade de Carnegie Mellon e Universidade Técnica de Munique.

MORIMOTO, Carlos H, Princípios de Interação Humano Computador, 2005. Material didático dos cursos MAC0446 e MAC5768 da Universidade de São Paulo. Disponível em http://www.ime.usp.br/ hitoshi/cursos/ihc/aulas/aula01-Introducao.pdf. Acessado em 02/06/2013. 
NAKRA, Teresa Marin. Inside the Conductor's Jacket: Analysis, Interpretation and Musical Synthesis of Expressive Gesture, 2000. Disponível em http://vismod.media.mit.edu/tech-reports/TR-518/. Acessado em 28/02/2012.

NEWCOMBE, Richard A; IZADI, Shahram; HILLIGES, Otmar; MOLYNEAUX, David; KIM, David; DAVIDSON, Andrew J; KOHLI, Pushmeet; SHOTTON, Jamie. NITE, NITE Algorithms 1.3, 2012. PrimeSense.

NUNES, Maria Augusta S. N; REHEM, Almerindo; BEZERRA, Jonas S; ROCHA, Alex; SANTOS, Celso A. S. Uso Do Kinect Para A Extração De Características Afetivas Do Usuário, 2011. Anais do XXII SBIE - XVII WIE. Universidade Federal de Sergipe e Universidade Federal da Bahia. Disponível em http://www.dcomp.ufs.br/ gutanunes/hp/publications/nunes.pdf. Acessado em $16 / 02 / 2012$.

OIKONOMIDIS, Iason. KYRIAZIS, Nikolaos. ARGYROS, Antonis. Efficient Model-based 3D Tracking of Hand Articulations using Kinect, 2011. Disponível em

http://www.ics.forth.gr/ argyros/mypapers/2011_09_bmvc_kinect_hand_tracking.pdf. Acessado em 16/02/2012.

PEDRINI, Hélio; SCHWARTZ, William Robson. Análise de Imagens Digitais: Princípios, Algoritmos e Aplicações, 2008. Thomson Learning, 2007.

PICARD, Rosalind; MARRIN, Teresa. The "Conductor's Jacket": A Device for Recording Expressive Musical Gestures, 1998. Disponível em http://vismod.media.mit.edu/pub/tech-reports/TR-470.pdf. Acessado em 28/02/2012.

PREMO. How does PrEmo work? 2013. Disponível em: http://www.premotool.com/about-premo/how-does-premo-work/. Acessado em 22/06/2013.

QUEIROZ, Murilo. Kinect MAME: Gladiator (Taito, 1986), 2011. Disponível em http://muriloq.com/blog/2011/01/kinect-mame-gladiator-taito-1986/. Acessado em $16 / 02 / 2012$. 
RAMOS, Marco Antonio da Silva. O ensino da regência coral, 2003. Trabalho apresentado como requisito parcial para concurso de habilitação à livre-docência junto à Escola de Comunicações e Artes da Universidade de São Paulo, 2003.

RAMOS, Marco Antonio da Silva. Escolas de Regência da tradição coral: Questões técnicas no Brasil e no panorama internacional, 2011. Concurso para Professor Titular em Regência Coral para o Departamento de Música (CMU) da Escola de Comunicações e Artes da Universidade de São Paulo.

RAMOS, Marco Antonio da Silva. Notas de Aula da disciplina: Análise Musical para Performance: Interfaces entre Criação e Interpretação a Partir do Universo Coral, 2011b. Departamento de Música (CMU) da Escola de Comunicações e Artes da Universidade de São Paulo.

VIRPI, Roto; MARIANNA， Obrist; KAISA， Väänänen-Vainio-Mattila. User Experience Evaluation Methods in Academic and Industrial Contexts, 2009. Tampere University of Technology, Nokia Research Center and University of Salzburg. Disponível em http://www.cs.tut.fi/ kaisavvm/UXEM09Interact_ObristRotoVVM.pdf. Acessado em 21/06/2013.

SANDBERG, David; FORSSÉN; Per-Erik; OGNIEWSKI, Jens. Model-Based Video Coding Using Colour and Depth Cameras, 2011. Disponível em http://www.acvt.com.au/wp-content/uploads/2011/12/sandberg_dicta111.pdf. Acessado em 03/01/2012.

SCHERER, Klaus R. What are emotions? How can they be measured? 2005. Disponível em http://ssi.sagepub.com/content/44/4/695.abstract. Acesado em 22/06/2013.

SCHMIDT, Dominik; SMAILAGIC, Asim; DANNENBERG, Roger B; SIEWIOREK, Daniel P. Learning an Orchestra Conductor's Technique Using a Wearable Sensor Platform, 2007. $11^{\circ}$. Simpósio Internacional do IEEE em Wearable Computers, 2007. 
SEI. What Is Software Architecture? 2013. Disponível em http://www.sei.cmu.edu/architecture/. Acessado em 18/06/2013.

SHAPIRO, Linda; STOCKMAN, George. Computer Vision, 2001.

SHOTTON, Jamie; FITZGIBBON, Andrew; COOK, Mat; SHARP, Toby; FINOCCHIO, Mark; MOORE, Richard; KIPMAN, Alex; BLAKE, Andrew. RealTime Human Pose Recognition in Parts from Single Depth Images, 2011. Disponível em http://www.cs.dartmouth.edu/ cs104/BodyPartRecognition.pdf. Acessado em 30/01/2012.

DA SILVEIRA, Marcus Almeida; Técnica de Navegação em Documentos Utilizando Microsoft $\quad$ Kinect, 2011. Disponível em http://www.lume.ufrgs.br/bitstream/handle/10183/36884/000819161.pdf?sequence=1. Acessado em 16/02/2012.

STEINMAN, Scott B; STEINMAN, Barbara A; GARZIA, Ralph P. Foundations of binocular vision: a clinical perspective, 2000. McGraw-Hill.

SUAY, Halit Bener; CHERNOVA, Sonia. Humanoid Robot Control using Depth Camera, 2011. HRI '11 Proceedings of the 6th international conference on Humanrobot interaction.

SUMA, Evan A; LANGE, Belinda; RIZZO, Albert; KRUM, David M; BOLAS, Mark. FAAST: The Flexible Action and Articulated Skeleton Toolkit, 2011. Disponível em http://people.ict.usc.edu/ suma/papers/suma-vr2011-faast.pdf. Acessa do em $16 / 02 / 2012$

TECHNOLOGYREVIEW. PrimeSense, s.d. Disponível em http://www.technologyreview.com/tr50/primesense/. Acessado em 27/12/2011.

THOMAS, Kurt. The Choral Conductor, 1971. The American Choral Foundation, American Choral Review Volume XIII, Números 1 e 2.

TOGORES, Tiago Andrade. Vitruvius: Um Reconhecedor de Gestos para o Kinect, 2011. Disponível em 
http://www.linux.ime.usp.br/ togores/mac499/pdf/monografia.pdf. Acessado em 03/08/2012.

USA, Satoshi; MOCHIDA, Yasunori. A Multi-Modal Conducting Simulator, 2006.

Disponível em http:/quod.lib.umich.edu/cgi/p/pod/dodidx?c=icmc;idno=bbp2372.1998.297. Acessado em 28/02/2012.

VILLAROMAN, Norman; ROWE, Dale; SWAN, Bret. Teaching Natural User Interaction Using OpenNI and the Microsoft Kinect Sensor, 2011. Disponível em http://sigite2011.sigite.org/wp-content/uploads/2011/10/session14-paper02.pdf. Acessado em 16/02/2012. 